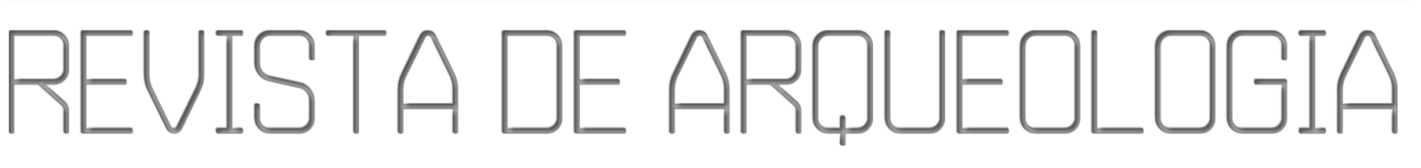

Volume 32 No.2 2019 Edição Especial: Museu Nacional (Volume 1)

\title{
A OCUPAÇÃO SAMBAQUIEIRA NO ENTORNO DA BAİA DE GUANABARA
}

Maria Dulce Gaspar*, Gina Faraco Bianchini ${ }^{\star *}$, Ana Luiza Berredo***, Mariana Samor Lopes ${ }^{\star * \star *}$

RESUMO

Rio de Janeiro, Niterói, Duque de Caxias, São Gonçalo e Magé, cidades situadas na baía de Guanabara, se desenvolveram em território antes ocupado pelos sambaquieiros. Durante o processo de urbanização, muitos sítios arqueológicos foram destruídos, e algumas pequenas porções estão cobertas por calçamentos de ruas e sob construções das cidades. Com o objetivo de investigar o sistema de assentamento, foram sistematizadas as informações sobre o nordeste da Baía, que ainda contem agrupamentos de sambaquis, alguns deles compostos por sítios em bom estado de conservação, e elaborada uma projeção para o entorno da Baía, com o objetivo de delinear suas principais características, traçar um panorama da ocupação sambaquieira no entorno da Baía e estabelecer correlações com outras regiões litorâneas.

Palavras-chave: Sambaqui; Sistema de Assentamento; Baía de Guanabara.

* Professora Colaboradora Voluntária do PPGArq-Museu Nacional/UFRJ, Pesquisadora do CNPq 201519. E-mail: madugasparmd@gmail.com. ORCID: https://orcid.org/0000-0002-5483-4495.

** Doutora pelo PPGArq/Museu Nacional. Arqueóloga da Artefato Arqueologia e Patrimônio. E-mail: ginabianchini@hotmail.com. ORCID: https://orcid.org/0000-0002-7991-976X.

*** Doutoranda em Arqueologia pela Universidade Federal do Rio de Janeiro, e mestre pela mesma instituição. E-mail: analuizaberredo@gmail.com. ORCID: https://orcid.org/0000-0002-6924-747X.

**** Doutoranda em Biologia Marinha e Ambientes Costeiros pela PBMAC/Universidade Federal Fluminense, e mestre pela mesma instituição. Laboratório de Paleoceanografia e Mudanças Globais (LP\&MG-UFF). E-mail: lopes_mariana@id.uff.br. ORCID: https://orcid.org/0000-0002-4422-8651. 


\section{THE SHELLMOUNDS OCCUPATION AROUND GUANABARA BAY}

\section{ABSTRACT}

Rio de Janeiro, Niterói, Duque de Caxias, São Gonçalo and Magé, located on the shores of Guanabara Bay, have developed in territory previously occupied by shellmound-builders. Throughout the process of urbanization, many sites were destroyed and some small portions are covered by sidewalks of streets and buildings of cities. In order to investigate the settlement of this system, were systematized information about the northeast of the bay which still contains groupings of shellmounds, some of them composed of sites in a good state of conservation. A projection has been drawn up for around the bay with the objective of outlining its main characteristics, draw a picture of the former sambaqui occupation and establish correlations with other coastal regions.

Keywords: Shellmounds; Settlement System; Guanabara Bay.

\section{LA OCUPACIÓN SAMBAQUIEIRA EN EL ENTORNO DE LA BAHÍA DE GUANABARA}

RESUMEN

Rio de Janeiro, Niterói, Duque de Caxias, São Gonçalo y Magé, ubicadas en la bahía de Guanabara, se desarrollaron en territorio antes ocupado por los sambaquieiros. Durante el proceso de urbanización muchos sitios arqueológicos fueron destruidos y algunas pequeñas porciones están cubiertas por calzones de calles y bajo construcciones de las ciudades. Para investigar el sistema de asentamiento se sistematizaron las informaciones sobre el nordeste de la bahía que aún contiene agrupaciones de sambaquis, algunos de ellos compuestos por sitios en buen estado de conservación, y elaborada una proyección para el entorno de la bahía para delinear sus principales características, trazar un panorama de la ocupación sambaquieira en el entorno de la bahía y establecer correlaciones con otras regiones costeras.

Palabras clave: Sambaqui; Sistema de Asentamiento; Bahía de Guanabara. 


\section{INTRODUÇÃO}

A Baía de Guanabara $(B G)$ reúne várias características que foram atraentes para a implantação de assentamentos dos pescadores-coletores que colonizaram a faixa litorânea brasileira. Águas tranquilas e quase sempre navegáveis, inúmeros ambientes como os amplos e férteis manguezais, costões rochosos e desembocaduras de rios ofereciam condições propícias para implantação e manutenção do modo de vida dos sambaquieiros. As pesquisas em sua porção nordeste informam que esta área estava ocupada desde 5000 mil anos atrás, e estudos em regiões adjacentes, como a praia de Camboinhas, sugerem que a presença dos pescadores-coletores deve ter sido bem anterior a isso.

A densa e centenária urbanização de suas margens, que se estendeu paulatinamente sobre áreas que haviam sido ocupadas por sambaquieiros, remobilizou, aterrou e eliminou inúmeros testemunhos arqueológicos dos pescadores-coletores. Rio de Janeiro, Niterói, Duque de Caxias, São Gonçalo e Magé são cidades antigas, que se desenvolveram em pleno território sambaquieiro, condição que dificulta a construção de um cenário que contemple a distribuição espacial dos sambaquis.

Com o objetivo de caracterizar a paisagem sambaquieira, será apresentada uma análise do meio físico, destacando-se as porções da Baía que reuniam condições atrativas para implantação de sambaquis, informações que serão sobrepostas aos registros de testemunhos arqueológicos existentes. Informações díspares e isoladas serão retomadas a partir do conhecimento já estabelecido sobre o sistema de assentamento dos pescadores-coletores, principalmente a constatação de que a ocupação do território se deu através de agrupamentos de sítios. A área que foi sistematicamente estudada ao longo de décadas de pesquisa, nordeste da Baía de Guanabara, será tomada como parâmetro no que se refere à distribuição e densidade de sítios e norteará as inferências sobre porções onde só estão disponíveis informações pontuais e isoladas.

\section{A BAIA DA GUANABARA: UM SITIO DE COMUNIDADES PESQUEIRAS}

Atualmente, a Baía de Guanabara possui uma bacia de drenagem de cerca de 4.080 $\mathrm{km}^{2}$ (Figura 1). Suas ilhas abrangem $56 \mathrm{~km}^{2}$, restando ainda uma área de $328 \mathrm{~km}^{2} \mathrm{de}$ superfície com água (KJERVE et al., 1997). Aproximadamente $84 \%$ das águas da baía têm profundidades inferiores a $10 \mathrm{~m}$, sendo que, na porção que corresponde ao canal principal que se estende da boca da baía até a linha entre o aeroporto Santos Dumont e Gragoatá, possui mais de $40 \mathrm{~m}$ de profundidade e uma largura média de $400 \mathrm{~m}$ (FIGUEIREDO et al, 2014).

Trata-se de um dos ecossistemas marinhos mais produtivos do mundo (SEVRINREYSSAC et al., 1979). Durante o verão austral, a entrada de água fria na baía (13-15 $\mathrm{C})$ está associada ao sistema de ressurgência da Ilha de Cabo Frio, centrado $100 \mathrm{~km}$ ao leste da entrada desse ecossistema (MARTIN et al., 1981/1982). Essas águas ricas em nutrientes favorecem a exploração de recursos pesqueiros, além de exercer um papel importante na distribuição de peixes (JICA, 1994). Pesquisas indicam a presença de 245 espécies, entre marinhas (174) e dulcícolas (71) (VIANNA et al. 2012).

O destaque nacional e internacional da Baía de Guanabara não é apenas por sua beleza cênica, mas também pela farta disponibilidade de recursos derivados da riqueza de seus ecossistemas: águas da baía, rios, manguezais e florestas, além da disponibilidade de terras extensas (SILVA et al., 2016; RAMINELLI, 2002). Por isso, é um dos principais setores pesqueiros do Estado do Rio de Janeiro que sustenta uma atividade de grande importância econômica e social (BEGOT \& VIANNA, 2014; PROZEE, 2005). 
Figura 1 - Localização da Baía de Guanabara dentro do estado do Rio de Janeiro e Brasil/América do Sul (CATANZARO et al., 2004).

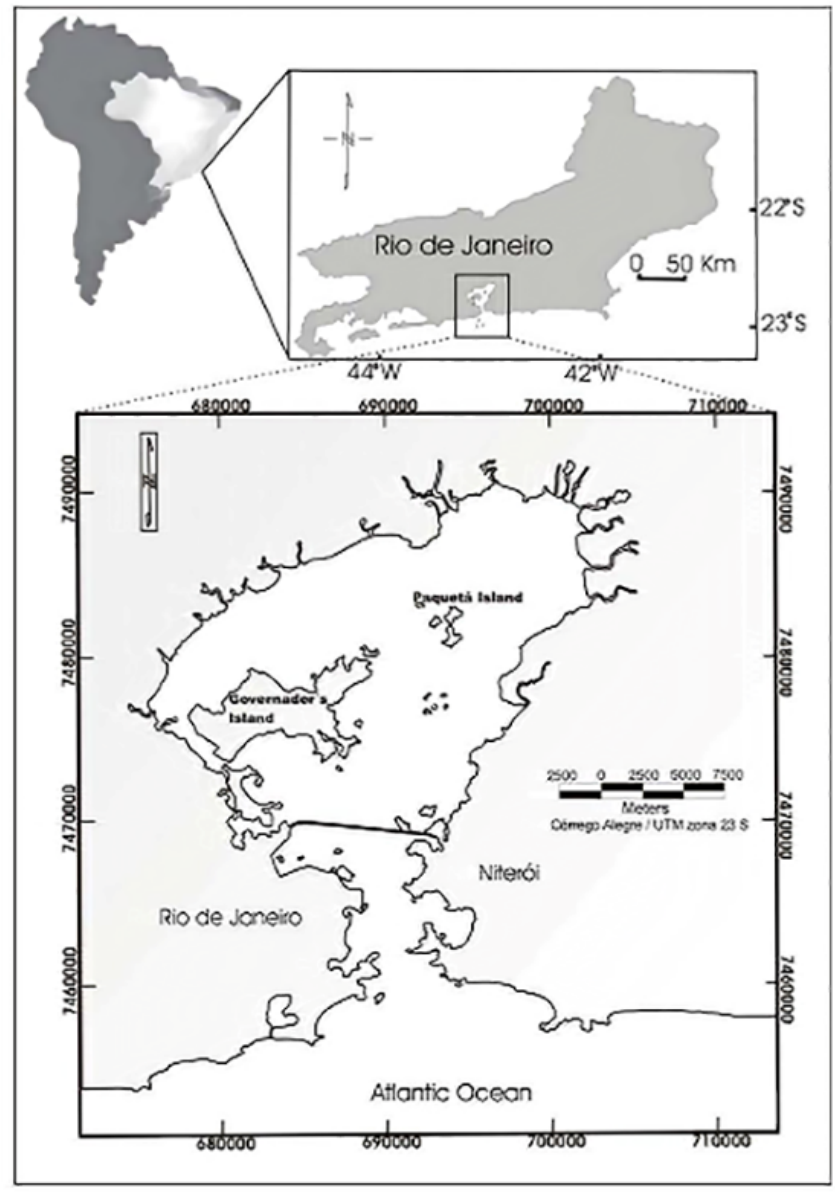

As características acima se apoiam em pesquisas recentes, no entanto fornecem um panorama das características da Baía de Guanabara, ilustrando um quadro através do qual é possível compreender seu potencial atrativo para ocupação humana ao longo do tempo. A Baía de Guanabara e seus ecossistemas associados, com alta produtividade e diversidade de recursos, é um ambiente extremamente propício para a instalação e manutenção de densas comunidades, processo que foi inaugurado com os construtores de sambaquis há pelo menos 6000 anos antes do presente.

$\mathrm{Na}$ atualidade os pescadores artesanais ${ }^{1}$ estão associados a sete Colônias de Pesca distribuídas por toda a orla, sendo elas: a Colônia Z8, que atua nos pontos de desembarque de Jurujuba, Ponta da Areia, Praia Grande, Ilha da Conceição, Gradim, Itaoca e Itambi, e participa diretamente da comercialização do pescado. As demais colônias têm atividades difusas; colônia Z9, que tem como jurisdição a área de Magé; Z10, localizada na Ilha do Governador, foi criada em 1920, sendo a primeira colônia de pescadores a ser reconhecida no Brasil; ainda, as colônias Z11, localizada em Ramos, Z12, no Caju, Z7 em Itaipú, Z8 em Niterói e São Gonçalo e a Z13 em Copacabana

\footnotetext{
${ }^{1}$ Pesca artesanal é aquela "realizada sem embarcações ou com embarcações de pequeno poder de deslocamento e autonomia e desprovidas de porão para estocagem; que utiliza aparelhos de pesca manuais ou de menor poder de pesca; que se limita a operar em áreas costeiras, estuarinas e/ou lagunares; que geralmente está vinculada a comunidades tradicionais com componentes culturais marcantes; que gera produtos consumidos localmente in natura ou regionalmente; exercida por pescadores sem vínculo empregatício (não celetistas)" (FIPERJ, 2014: 24,25).
} 
(JABLONSKI et al., 2002; OLIVEIRA, 2016). Além delas, existem também diversas associações e cooperativas (CHAVES, 2011).

É muito difícil precisar o número de pescadores que atuam na Baía de Guanabara, estimativas variam desde 5.000 até 18.000 entre artesanais e industriais (OLIVEIRA, 2016). Estes possuem uma ligação com áreas da Baía de Guanabara que são muito significativas para a pesca, seja pela variedade ou qualidade dos peixes. Determinadas espécies não ocorrem em qualquer parte da baía e, dependendo do seu valor econômico, os pescadores vão ao encontro destes recursos (CHAVES, 2011). Pesqueiros são espaços aquáticos particularmente importantes para essas comunidades tradicionais, são locais que servem de habitat ou comedouro de peixes, onde se concentra a maior biodiversidade, e por esse motivo são pontos disputados (CHAVES, 2011). Dessa maneira, há pontos importantes destacados para a prática da pescaria tradicional, como áreas antigas de pesca, e é plausível supor que áreas que se caracterizam pela concentração de recursos também eram conhecidas e valorizadas pelos sambaquieiros.

Abundantes recursos renováveis propiciam a exploração conjunta por membros que integram diferentes comunidades, tanto na atualidade como no passado. A disposição dos recursos valorizados pelos sambaquieiros em distintas porções das águas da Guanabara propiciava o compartilhamento desse fértil “aquatório” (KNEIP et al., 2018).

\section{OCUPAÇÃO SAMBAQUIEIRA DA BAÍA DE GUANABARA}

A Baía de Guanabara está inserida na vertente Atlântica da Serra do Mar. Permeada por ilhas, alarga-se no meio de uma planície entre colinas formadas por pequenos maciços litorâneos. A alta pluviosidade na escarpa da Serra do Mar dá origem a um grande número de pequenos cursos que atravessam a planície em direção à baía, onde suas águas são rechaçadas pela maré. Em alguns rios, a influência da maré pode se estender a distâncias de até seis quilômetros. $\mathrm{Na}$ época das chuvas, de outubro a março, os rios transbordam, e as águas se alastram, inundando as depressões (RUELLAN, 1944).

Manguezais ocorrem especialmente nas desembocaduras dos rios, a vegetação de restinga ocupa os terraços marinhos e nas cotas mais elevadas dominam as exuberantes formações de Floresta Ombrófila Densa. A configuração desse ambiente extremamente diversificado se deu ao longo de milhares de anos e está associada principalmente à intensa dinâmica que ocorreu durante o Quaternário.

De acordo com estudos geológicos, o último interglacial ocorrido no Pleistoceno não deixou registros no entorno da baía, diferente do que vem sendo descrito para outros segmentos costeiros no sul e sudeste do país (AMADOR, 1997). Nesse período, entre $200 \mathrm{Ka}$ a $120 \mathrm{Ka}$, intervalo que diverge entre diferentes autores (AMADOR, 1997; SUGUIO et al.,1985), o nível eustático estaria de seis a oito metros acima do atual, produzindo muitas das feições erosivas (falésias) observadas nas porções costeiras dos maciços litorâneos da região.

Em torno de $18 \mathrm{Ka}$, quando ocorreu o último máximo glacial, o nível do mar estaria $100 \mathrm{~m}$ abaixo do atual, expondo parte da plataforma continental e do entalhamento de drenagens no interior do Graben da Guanabara. A batimetria da baía revela uma rede de paleodrenagens que convergem para um canal principal, onde são detectadas as maiores profundidades, denominado de Paleorio Guanabara (AMADOR, 1997), (Figura 2).

A partir daí, o derretimento progressivo das calotas polares localizadas em latitudes elevadas deu origem a diversos eventos transgressivos parcialmente interrompidos por pequenas regressões e estabilizações de linhas de costa, e a Baía de Guanabara passou gradualmente a servir como área de captação e retrabalhamento sedimentar (CORREAA et al., 1980). 
Assim, durante o máximo transgressivo, que ocorreu entre 6.000 a 5.000 anos A.P. (para o litoral brasileiro (SUGUIO et al., 1985); para o entorno da Baía de Guanabara (AMADOR, 1997); para o litoral catarinense (CARUSO et al., 2000); para o litoral gaúcho (TOMAZELLI \& VILWOCK, 2005); e para o litoral sul catarinense (GIANNINI et al., 2007)), a região da baía foi afogada, formando uma superfície de lâmina d'água duas vezes maior do que a atual, de tal modo que áreas hoje distantes cerca de $30 \mathrm{~km}$ do litoral eram, nessa época, alcançadas por águas marinhas. $\mathrm{O}$ mar, cerca de três a quatro metros acima do nível atual, avançou pelos pequenos vales fluviais e planícies na base da Serra do Mar, formando enseadas e cordões arenosos através da ação de ondas e marés, em torno da linha de uma paleobaía (AMADOR, 1997).

Em decorrência da evolução costeira na região da Baía de Guanabara é pertinente considerar que os sambaquis mais antigos tenham sido destruídos pela ação das águas. A partir de 5.000, o nível do mar começa a recuar até atingir o nível atual, dando lugar a ambientes de dunas, brejos e pântanos, onde posteriormente foram se instalando as vegetações de restinga e manguezais, reduzindo progressivamente a superfície da baía até os dias de hoje. Nesse período, próximo ao máximo transgressivo, há registro de sambaquis como o Guapi.

Figura 2 - Baía de Guanabara durante o Quaternário, depósitos associados (AMADOR, 1980; ANGULO \& LESSA, 1997) e respectivos paleocenários: (a) Último período glacial - 20.00018.000 A.P no qual observa-se o Paleorio Guanabara; (b) Máximo transgressivo - 6.000-5.000 A.P, destacando a Paleobaía (modificado de AMADOR, 1997).
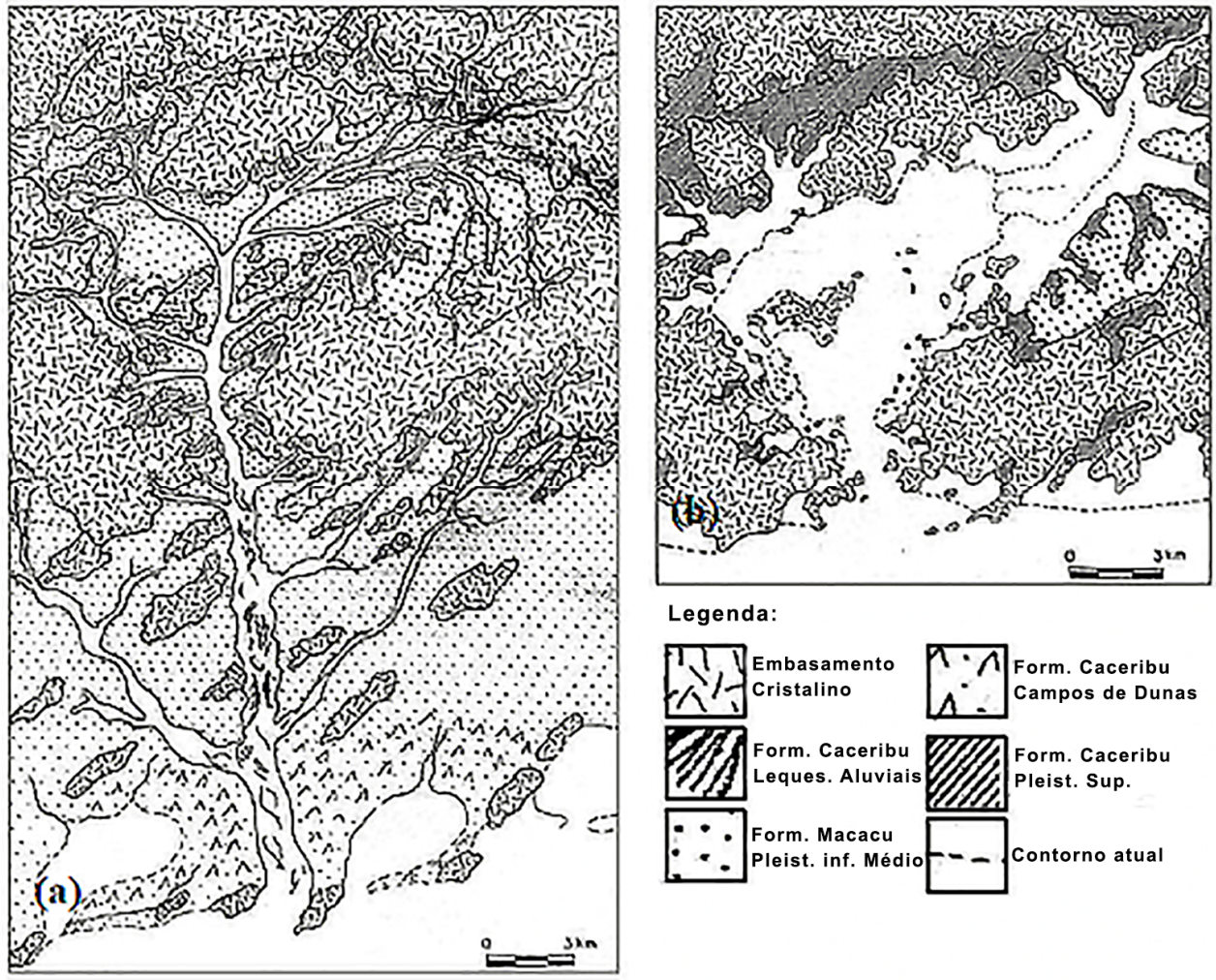

A presença dos sambaquis na Baía de Guanabara chamou atenção desde o início, mas também sua intensa exploração decorrente especialmente da indústria da cal (CAPANEMA, 1876). Provavelmente os estudos no Rio de Janeiro se voltaram para outros pontos de interesse mais afastados da grande metrópole e de seus arredores. 
Assim, as pesquisas arqueológicas sistemáticas no entorno da Baía de Guanabara tiveram início somente após a segunda metade da década de 1970, quando os primeiros sambaquis foram alvo de escavações, entre eles Sernambetiba e Amourins (Figura 3); Saracuruna; Rio das Pedrinhas e Arapuan (BELTRÃO et al., 1982; HEREDIA et al., 1982; MENDONÇA DE SOUZA \& MENDONÇA DE SOUZA, 1981/1982; MELLO \& SOUZA, 1977; BEZERRA, 1995).

O estudo desenvolvido por Villagran et al. (2010) é especialmente relevante para as reflexões aqui apresentadas, através de análises microestratigráficas que destacaram semelhanças entre o processo de formação do sambaqui de Sernambetiba e sambaquis do litoral sul de Santa Catarina. No que se refere ao sambaqui de Amourins, Gaspar et al (2013) realizaram releitura das informações (HEREDIA et al., 1982), além da sistematização das observações de campo, e destacaram que a grande maioria dos artefatos identificados estavam espacialmente correlacionados com sepultamentos. Dessa maneira, sugeriram que o Amourins também tinha sido formado a partir de rituais funerários. Mendonça de Souza et al. (2012) apresentam relato detalhado das últimas intervenções no sambaqui de Amourins, especialmente no que se refere à retirada de esqueletos, e estabelecem que a construção desse sítio foi estreitamente relacionada aos funerais.

Figura 3 - (a) Vista panorâmica da seção Oeste do Sambaqui Amourins; (b) Sambaqui Sernambetiba, locus 1, seção da parede Leste, onde foi realizada coleta de amostras para análise zooantracológica.

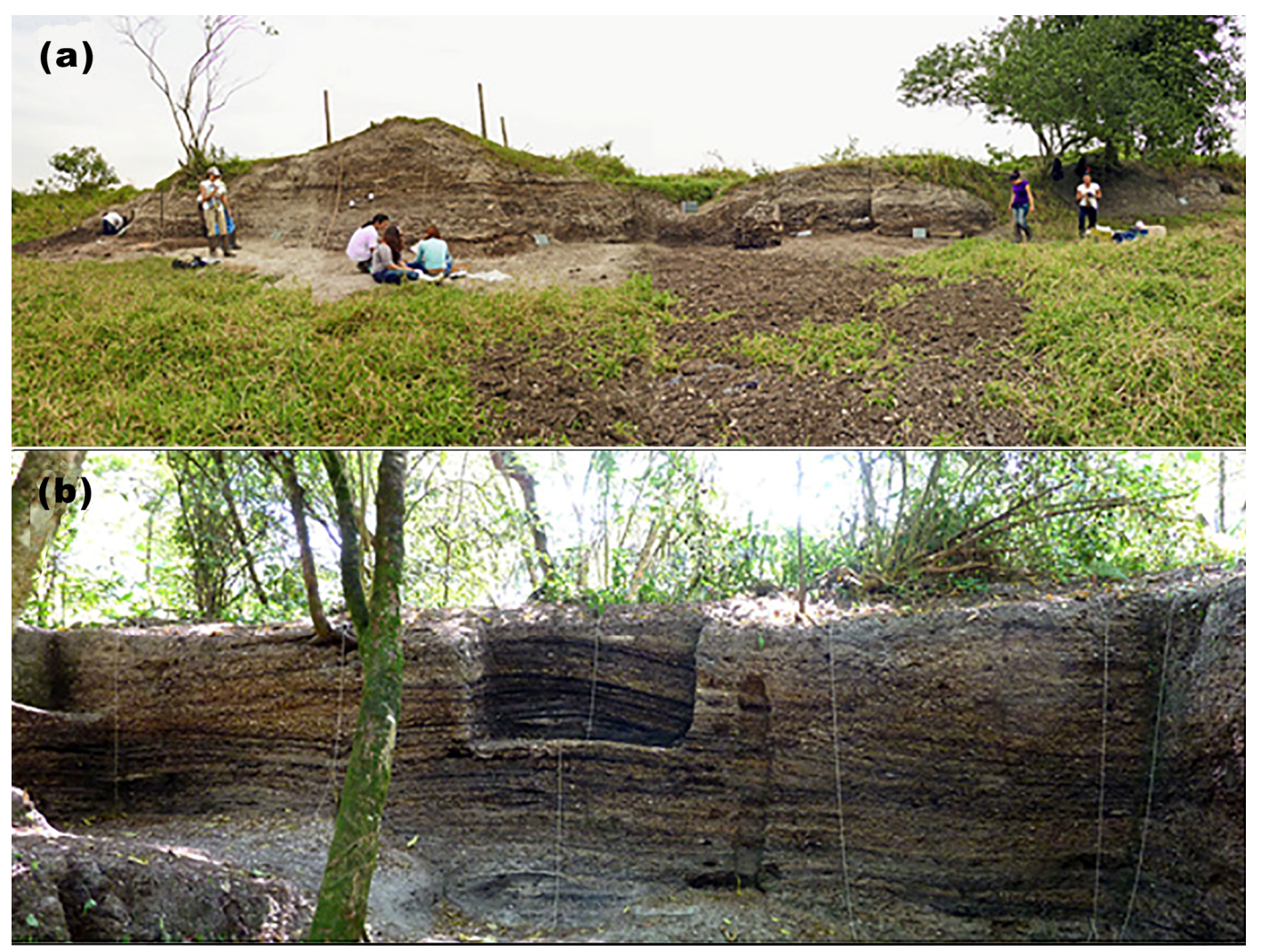

Atualmente ainda não há um modelo de ocupação detalhado para a Baía de Guanabara, tampouco uma comparação mais consistente com outras regiões do litoral onde ocorrem concentrações de sambaquis. Isto porque o número de pesquisas ainda é incipiente e, especialmente, a quantidade de datações obtidas. Porém, ainda assim, alguns 
aspectos podem ser apontados com certa segurança, pois se apoiam também na recorrência de evidências obtidas para outras regiões onde os estudos estão mais avançados.

De modo geral, pode-se afirmar que a ocupação sambaquieira no entorno da Baía de Guanabara foi um processo intenso e de longa duração, tal como vem sendo identificado em outras regiões do litoral brasileiro. Apesar do processo de urbanização ter acarretado na destruição de muitos sítios, atualmente são conhecidos mais de 49 sambaquis (Tabela 1). Eles ocorrem no entorno de toda a baía, desde o Centro do Rio de Janeiro, Ilha do Governador, Duque de Caxias, Magé, Guapimirim, Itaboraí, São Gonçalo até Niterói. Muitos deles estão assentados próximos aos grandes rios, como os rios Macacu, Estrela e Iguaçu por exemplo, sugerindo um padrão de ocupação ribeirinho, embora às margens da baía.

Tabela 1 - Sambaquis localizados no entorno da Baía de Guanabara.

\begin{tabular}{|c|c|c|c|c|}
\hline Número & Sambaqui & Caracterização & Localização & Fonte \\
\hline 1 & Amourins & $\begin{array}{c}\text { 60m de comprimento x } 10 \mathrm{~m} \\
\text { de largura e } 2,80 \mathrm{~m} \text { de altura. } \\
\text { Presença de sepultamentos } \\
\text { humanos }\end{array}$ & Guapimirim & $\begin{array}{c}\text { Mendonça de Sousa, } 1973 \\
\text { e 1978; } \\
\text { Heredia \& Beltrão, } 1979 \\
\text { Cardoso, 2013; } \\
\text { Berredo, 2018 }\end{array}$ \\
\hline 2 & Arapuan & $\begin{array}{c}\text { Área circular de } 2000 \mathrm{~m}^{2} \text { e } \\
4,5 \mathrm{~m} \text { de altura. Entre o Rio } \\
\text { Guapi e canal Caioba. } \\
\text { Presença de sepultamentos } \\
\text { humanos }\end{array}$ & Guapimirim & $\begin{array}{c}\text { Mendonça de Sousa, } 1973 \\
\text { e 1978; Bezerra, } 1977 \text { e } \\
\text { 1978; Oliveira, } 1978\end{array}$ \\
\hline 3 & Boa Vista & Sítio parcialmente destruído & Niterói & - \\
\hline 4 & Bulcão I & $\begin{array}{l}\text { Localizada em propriedade } \\
\text { particular na estrada Itambi- } \\
\text { Visconde. A } 9 \text { km da Baía de } \\
\text { Guanabara. }\end{array}$ & Guapimirim & $\begin{array}{c}\text { Gaspar, } 2007 \\
\text { Pinto, } 2009\end{array}$ \\
\hline 5 & Bulcão II & $\begin{array}{l}\text { Localizada em propriedade } \\
\text { particular na estrada Itambi- } \\
\text { Visconde. A } 1 \mathrm{~km} \text { do Bulcão I. }\end{array}$ & Guapimirim & $\begin{array}{c}\text { Gaspar, } 2007 \\
\text { Pinto, } 2009\end{array}$ \\
\hline 6 & Cafubá & $\begin{array}{c}\text { Próximo à Lagoa de } \\
\text { Piratininga. } \\
\text { vestígios orgânicos: } \\
\text { Malacológico, restos } \\
\text { faunísticos diversos e ósseo } \\
\text { humano. } \\
\end{array}$ & Niterói & Kneip, 1979. \\
\hline 7 & Camboinhas & $\begin{array}{l}\text { Localizado próximo à lagoa de } \\
\text { Itaipu na praia de Camboinhas }\end{array}$ & Niterói & $\begin{array}{c}\text { Kneip, 1979; Palestrini \& } \\
\text { Morais, } 1980\end{array}$ \\
\hline 8 & $\begin{array}{l}\text { Chácara do } \\
\text { Vintém }\end{array}$ & $\begin{array}{l}\text { Presença de conchas do tipo } \\
\text { berbigão }\end{array}$ & Niterói & - \\
\hline 9 & Cordovil & $\begin{array}{c}\text { Área de } 1.500 \mathrm{~m}^{2} \text {. Localiza-se a } \\
200 \mathrm{~m} \text { a noroeste do sambaqui } \\
\text { do Fernando. }\end{array}$ & Guapimirim & $\begin{array}{c}\text { Mendonça de Sousa, } 1973 \\
\text { e 1978; } \\
\text { Paz, } 1999 \\
\end{array}$ \\
\hline 10 & Dona Nora & $\begin{array}{c}\text { Localizado a } 360 \text { m da BR } 493 . \\
\text { Inicia na Praça de São } \\
\text { Barnabé, se estende para a } \\
\text { residência de Dona Nora, } \\
\text { descendo a encosta e é cortado } \\
\text { por uma rua de terra. } \\
\text { Apresenta terra preta, ossos de } \\
\text { fauna, seixos e Anomalocardia } \\
\text { brasiliana. } \\
\text { Área: } 4950 \mathrm{~m}^{2}\end{array}$ & Itaboraí & CNSA \\
\hline
\end{tabular}




\begin{tabular}{|c|c|c|c|c|}
\hline Número & Sambaqui & Caracterização & Localização & Fonte \\
\hline \multicolumn{5}{|c|}{$\begin{array}{c}\text { Próximo da Bacia do Rio } \\
\text { Tambicu }\end{array}$} \\
\hline 11 & $\begin{array}{l}\text { Estrada de } \\
\quad \text { Ferro }\end{array}$ & $\begin{array}{l}\text { A } 1.2 \mathrm{~km} \text { a noroeste do } \\
\text { Sampaio I. A } 12 \mathrm{~km} \text { da Baía de } \\
\text { Guanabara. Profundidade do } \\
\text { pacote arqueológico: } 80 \mathrm{~cm}\end{array}$ & Itaboraí & $\begin{array}{l}\text { Gaspar, } 2007 \\
\text { Pinto, } 2009\end{array}$ \\
\hline 12 & $\begin{array}{l}\text { Fazenda } \\
\text { Caieira }\end{array}$ & $\begin{array}{l}\text { A } 6 \text { km da Baía de Guanabara. } \\
\text { Próximo ao rio da Caieira }\end{array}$ & Itaboraí & Clerot, 1928 \\
\hline 13 & Fernando & $\begin{array}{c}\text { Área de } 1.500 \mathrm{~m}^{2} . \text { Localizado } \\
\text { entre os rios Magé e } \\
\text { Guapimirim }\end{array}$ & Guapimirim & $\begin{array}{c}\text { Mendonça de Sousa, } 1973 \\
\text { e 1978; } \\
\text { Paz, } 1999\end{array}$ \\
\hline 14 & Galeão & $\begin{array}{c}\text { Sambaqui localizado no bairro } \\
\text { Galeão, próximo a Base Aerea } \\
\text { do Galeão. O sitio encontra-se } \\
\text { altamente destruído, pela } \\
\text { construção da Av. Coronel } \\
\text { Meier.] } \\
\text { A 900m da Baía de Guanabara. } \\
\text { Sítios relacionados: Sambaqui } \\
\text { das Pixunas (GB18), Sambaqui } \\
\text { da Praia do Espinheiro (GB21), } \\
\text { Sambaqui ou aldeamento } \\
\text { Tupi-Guarani do Jequiá } \\
\text { (GB22) }\end{array}$ & $\begin{array}{l}\text { Rio de } \\
\text { Janeiro }\end{array}$ & $\begin{array}{c}\text { BELTRÃO, M. } 1978 . \\
\text { Maria Dulce Gaspar,2005 }\end{array}$ \\
\hline 15 & Guapi & $\begin{array}{l}\text { Pequena elevação monticular } \\
\text { com } 2,5 \text { m de altura }\end{array}$ & Guapimirim & $\begin{array}{c}\text { Mendonça de Sousa, } 1973 \\
\text { e 1978; } \\
\text { Mendonça de Souza e } \\
\text { Mendonça de Souza, 1980 } \\
\text { Borges, } 2015\end{array}$ \\
\hline 16 & Guaraí-mirim & $\begin{array}{l}\text { Localizado na margem direita } \\
\text { do rio Macacú, na área } \\
\text { inundável entre este rio e o } \\
\text { Guaraí-Mirim, às margens da } \\
\text { Vala de Sernambetiba. } \\
\text { Área elipsoidal com } 48 \text { x } 18 \mathrm{~m} \\
\text { x } 5 \mathrm{~m} \text { de altura }\end{array}$ & Guapimirim & $\begin{array}{c}\text { Clerot, 1928; Mendonça } \\
\text { de Sousa, 1973 e 1978; } \\
\text { Beltrão, 1978; } \\
\text { Paz, } 1999\end{array}$ \\
\hline 17 & Iguaçu & $\begin{array}{c}\text { Comprimento: } 80 \mathrm{~m} \\
\text { Largura: } 120 \mathrm{~m} \\
\text { Próximo do Rio Iguaçu. }\end{array}$ & $\begin{array}{l}\text { Duque de } \\
\text { Caxias }\end{array}$ & $\begin{array}{l}\text { Jeanne Cordeiro de } \\
\text { Oliveira }(2004)\end{array}$ \\
\hline 18 & Iguapi & $\begin{array}{c}\text { Altura: } 2 \mathrm{~m} \text {. Próximo ao Rio } \\
\text { Iguaí. Presença de lítico } \\
\text { lascado, malacológico e } \\
\text { carvões. }\end{array}$ & Magé & Beltrão, 1973 \\
\hline 19 & $\begin{array}{l}\text { Ilha do } \\
\text { Cafubá }\end{array}$ & $\begin{array}{c}\text { Remanescentes da base de um } \\
\text { sambaqui alojado na encosta } \\
\text { de um afloramento rochoso. } \\
\text { Área: } 150 \mathrm{~m}^{2} \\
\text { Próximo à Lagoa de } \\
\text { Piratininga }\end{array}$ & Niterói & Kneip, 1979. \\
\hline 20 & Imenezes & $\begin{array}{c}\text { Área circular de } 2.000 \mathrm{~m}^{2} \mathrm{e} \\
1.2 \mathrm{~m} \text { de altura. Entre os rios } \\
\text { Magé e Guapimirim }\end{array}$ & Guapimirim & Mendonça de Souza, 1973 \\
\hline 21 & Itambi & $\begin{array}{l}\text { Ao longo da estrada de ferro, } \\
\text { próximo ao rio Macacu }\end{array}$ & Itaboraí & $\begin{array}{c}\text { Clerot, 1928; Leonardos, } \\
1938\end{array}$ \\
\hline 22 & Jequiá & $\begin{array}{c}\text { Sambaqui com cerâmicas tupi- } \\
\text { guarani em seu interior. } \\
\text { Depósito arqueológico com } \\
\text { Anomalocardia brasiliana, }\end{array}$ & $\begin{array}{l}\text { Rio de } \\
\text { Janeiro }\end{array}$ & $\begin{array}{l}\text { Beltrão, } 1973 \\
\text { Beltrão, } 1978\end{array}$ \\
\hline
\end{tabular}




\begin{tabular}{|c|c|c|c|c|}
\hline Número & Sambaqui & Caracterização & Localização & Fonte \\
\hline & & $\begin{array}{c}\text { numerosos cacos de cerâmica } \\
\text { Tupi, lisa e decorada, e } \\
\text { materiais de orígem européia. }\end{array}$ & & \\
\hline 23 & Marquesa & $\begin{array}{l}\text { Localizado no loteamento } \\
\text { Marquesa de Santos, praça } \\
\text { Central. Artefatos líticos } \\
\text { (lascas de quartzo) e conchas } \\
\text { de Ostrea sp. }\end{array}$ & $\begin{array}{l}\text { Duque de } \\
\text { Caxias }\end{array}$ & Dias Jr, 1973 \\
\hline 24 & Meia-noite & $\begin{array}{c}\text { Dimensões: } \\
90 \times 50 \mathrm{~m} \\
\text { Altura: } 5 \mathrm{~m} ; \\
\text { Observa-se presença de ostras } \\
\text { e berbigões. } \\
\text { Próximo ao rio caceribu. } \\
\text { Sítios relacionados: sampaio } 1\end{array}$ & Guapimirim & CNSA \\
\hline 25 & Paiol & $\begin{array}{c}\text { Sitio sambaqui, localizado às } \\
\text { margens do Rio Estrela, em } \\
\text { uma área de mangue, } \\
\text { caracterizado pela presença de } \\
\text { conchas em superfície. } \\
\text { Encontra-se totalmente } \\
\text { destruído. } \\
\text { Sítios relacionados: ruinas de } \\
\text { Paiol de Pólvora, Sítio Estrela, } \\
\text { Sambaqui de Saracuruna, } \\
\text { Sambaqui do Porto de Estrela, } \\
\text { sítio cerâmico Aldeia (GNL1). } \\
\text { Área: } 100 \mathrm{~m}^{2}\end{array}$ & Magé & Gaspar, 2014 \\
\hline 26 & Pixunas & $\begin{array}{c}\text { Área: } 5000 \mathrm{~m}^{2} \\
\text { Altura: } 3 \mathrm{~m} \\
\text { Próximo a Riacho }\end{array}$ & $\begin{array}{l}\text { Rio de } \\
\text { Janeiro }\end{array}$ & $\begin{array}{c}\text { Maria da Conceição de M. } \\
\text { C. Becker, } 1965 \\
\text { Beltrão, } 1978\end{array}$ \\
\hline 27 & $\begin{array}{l}\text { Ponta do } \\
\text { Pirata }\end{array}$ & $\begin{array}{c}\text { Localizada na Ponta do Pirata, } \\
\text { no loteamento de Barão do } \\
\text { Iriri, Baía de Guaratiba. Área } \\
\text { irregular, superior a } 500 \mathrm{~m}^{2} \text {. } \\
\text { Próximo ao rio Roncador e } \\
\text { Iriri }\end{array}$ & Magé & $\begin{array}{c}\text { Mendonça de Sousa, 1973; } \\
1978 .\end{array}$ \\
\hline 28 & $\begin{array}{l}\text { Porto da } \\
\text { Estrela }\end{array}$ & $\begin{array}{l}\text { Pequeno sambaqui com } 5 \mathrm{~m} \text { de } \\
\text { diâmetro e } 1,5 \mathrm{~m} \text { de altura. }\end{array}$ & Magé & $\begin{array}{c}\text { Dias Jr, 1973; } \\
\text { Mendonça de Sousa, 1973; } \\
1978 .\end{array}$ \\
\hline 29 & $\begin{array}{l}\text { Praia da Luz } \\
\text { ou Capilé }\end{array}$ & $\begin{array}{l}\text { Presença de conchas do tipo } \\
\text { berbigão }\end{array}$ & São Gonçalo & \\
\hline 30 & $\begin{array}{l}\text { Praia do } \\
\text { Espinheiro }\end{array}$ & $\begin{array}{l}\text { Depósito conchífero } \\
\text { praticamente destruído. } \\
\text { Continha numerosos cacos de } \\
\text { cerâmica. Teria, } \\
\text { originalmente, } 60 \mathrm{~m} \text { de } \\
\text { extensão e cerca de } 3 \mathrm{~m} \text { de } \\
\text { altura. Cortado pela estrada de } \\
\text { acesso à praia do Espinheiro. } \\
\text { Próximo do Rio Jequié }\end{array}$ & $\begin{array}{l}\text { Rio de } \\
\text { Janeiro }\end{array}$ & $\begin{array}{l}\text { Beltrão, } 1972 \\
\text { Beltrão, } 1978\end{array}$ \\
\hline 31 & Propósito & $\begin{array}{c}\text { Área: } 3850 \mathrm{~m}^{2} \\
\text { Comprimento: } 70 \mathrm{~m} . \\
\text { A } 1000 \mathrm{~m} \text { da Baía de } \\
\text { Guanabara. } \\
\text { Apresentou conchas e lítico } \\
\text { lascado. }\end{array}$ & $\begin{array}{l}\text { Rio de } \\
\text { Janeiro }\end{array}$ & Tânia Andrade Lima \\
\hline
\end{tabular}




\begin{tabular}{|c|c|c|c|c|}
\hline Número & Sambaqui & Caracterização & Localização & Fonte \\
\hline 32 & $\begin{array}{c}\text { Rio das } \\
\text { Pedrinhas }\end{array}$ & $\begin{array}{c}\text { Area elíptica de } 1.200 \mathrm{~m}^{2} \mathrm{e} \\
\text { altura de } 4,20 \mathrm{~m}\end{array}$ & Guapimirim & Mendonça de Souza, 1973 \\
\hline 33 & Rua 13 & $\begin{array}{c}\text { Construído abaixo de uma } \\
\text { casa. Vestígios arqueológicos } \\
\text { ao redor da construção. Foram } \\
\text { observadas conchas e líticos na } \\
\text { base }\end{array}$ & Guapimirim & $\begin{array}{l}\text { Gaspar, } 2007 \\
\text { Pinto, } 2009\end{array}$ \\
\hline 34 & Sampaio I & $\begin{array}{c}\text { Localizado em fazenda em } \\
\text { processo de desapropriação. } \\
\text { Área 100m x } 40 \text { m x 3m } \\
\text { (altura) }\end{array}$ & Itaboraí & $\begin{array}{l}\text { Beltrão, 1982; Paz, 1999; } \\
\text { Gaspar, 2007, Pinto, } 2009\end{array}$ \\
\hline 35 & Sampaio II & $\begin{array}{l}\text { Aterro com material } \\
\text { arqueológico. Foram } \\
\text { encontrados dentes de } \\
\text { tubarões perfurados }\end{array}$ & Itaboraí & $\begin{array}{l}\text { Gaspar, } 2007 \\
\text { Pinto, } 2009\end{array}$ \\
\hline 36 & São Bento & $\begin{array}{l}\text { Presença de conchas do tipo } \\
\text { berbigão }\end{array}$ & $\begin{array}{c}\text { Duque de } \\
\text { Caxias }\end{array}$ & $\begin{array}{l}\text { Jeanne Cordeiro de } \\
\text { Oliveira, } 2004\end{array}$ \\
\hline 37 & São Bento 2 & $\begin{array}{c}\text { Localizado a } 360 \mathrm{~m} \text { do } \\
\text { sambaqui de São Bento. } \\
\text { Caracteriza-se pelo } \\
\text { afloramento de malacofauna } \\
\text { sobre a superfície do terreno. } \\
\text { Área: } 1290 \mathrm{~m}^{2} \\
\text { Comprimento: } 70 \mathrm{~m} \\
\text { Largura: } 25 \mathrm{~m} \\
\text { Sítios relacionados: sambaqui } \\
\text { de sao bento e sambaqui de } \\
\text { Iguaçu. } \\
\text { Próximo do Rio Iguaçu. }\end{array}$ & $\begin{array}{l}\text { Duque de } \\
\text { Caxias }\end{array}$ & $\begin{array}{c}\text { Dias Jr, } \\
\text { Jeanne Cordeiro de } \\
\text { Oliveira, } 2004\end{array}$ \\
\hline 38 & São Lourenço & $\begin{array}{l}\text { Presença de conchas do tipo } \\
\text { berbigão }\end{array}$ & Niterói & - \\
\hline 39 & Saracuruna & $\begin{array}{l}\text { Localizado à margem direita } \\
\text { do rio Saracuruna, no } \\
\text { loteamento, a cerca de } 200 \mathrm{~m} \\
\text { do rio e a } 1 \mathrm{~km} \text { da estrada Rio- } \\
\text { Teresópolis. Possuía, } \\
\text { originalmente, } 20 \mathrm{~m} \text { de } \\
\text { diâmetro e } 6 \mathrm{~m} \text { de altura }\end{array}$ & Magé & $\begin{array}{c}\text { Mello \& Mendonça de } \\
\text { Souza, 1977; Mendonça de } \\
\text { Souza, 1978; Dias Jr. } \\
\text { (comunicação pessoal } \\
\text { 1981). }\end{array}$ \\
\hline 40 & Sendas & & Magé & PAZ, 1999 \\
\hline 41 & Sernambetiba & $\begin{array}{l}\text { - } 6 \mathrm{~m} \text { de altura por } 60 \mathrm{~m} \text { de } \\
\text { largura e } 100 \mathrm{~m} \text { de } \\
\text { comprimento. Localizado } \\
\text { entre o rio Guapimirim e o } \\
\text { canal Magé-Mirim. } \\
\text { Presença de sepultamentos } \\
\text { humanos }\end{array}$ & Guapimirim & $\begin{array}{c}\text { Mezzalira, 1946; Guerra, } \\
\text { 1962; Macedo, 1965; } \\
\text { Beltrão e Kneip, 1967; } \\
\text { Beltrão, 1972 e 1978; } \\
\text { Amador, 1974; Mendonça } \\
\text { de Souza, 1973 e 1978; } \\
\text { Hurt, 1986; Gaspar 1996; } \\
\text { Bianchini, 2015; Estanek, } \\
2015\end{array}$ \\
\hline 42 & Seu Jorge & $\begin{array}{c}\text { Dimensões: cerca de } 80 \text { x } 40 \text { m } \\
\text { e } 5 \text { m de altura. A } 14 \mathrm{~km} \text { da } \\
\text { Baía de Guanabara }\end{array}$ & Guapimirim & $\begin{array}{l}\text { Gaspar, } 2007 \\
\text { Pinto, } 2009\end{array}$ \\
\hline 43 & Sossego & $\begin{array}{c}\text { Antiga ilha, sobre um morro. } \\
\text { Próximo da praia do Sossego, } \\
\text { de Piratininga e de } \\
\text { Camboinhas. } \\
\text { pedaços de carvão dispesos, } \\
\text { Presença de conchas com } \\
\text { predominância de mexilhão. } \\
\text { Segundo informações, havia }\end{array}$ & Niterói & CNSA \\
\hline
\end{tabular}




\begin{tabular}{|c|c|c|c|c|}
\hline Número & Sambaqui & Caracterização & Localização & Fonte \\
\hline & & $\begin{array}{c}\text { também, vértebras de peixe. } \\
\text { Lítico, louça e cerâmica } \\
\text { neobrasileira. }\end{array}$ & & \\
\hline 44 & Tambicu & $\begin{array}{l}\text { Localizado na fazenda Santo } \\
\text { Antônio, próximo ao riacho } \\
\text { Tambicu. Área elipsoidal com } \\
3.500 \mathrm{~m}^{2}(27 \mathrm{x} 18 \mathrm{~m}) \text { e } 3 \mathrm{~m} \text { de } \\
\text { altura. Presença de ossos } \\
\text { humanos mineralizados. }\end{array}$ & Itaboraí & Clerot, 1928. \\
\hline 45 & Zé Garoto & $\begin{array}{c}\text { Pequena elevação coberta de } \\
\text { vegetação rasteira. O sambaqui } \\
\text { encontra-se intacto, bem } \\
\text { próximo ao mangue. O exame } \\
\text { de um perfil permitiu } \\
\text { visualizar uma camada } \\
\text { arqueológica de } 50 \mathrm{~cm} \text { de } \\
\text { espessura. }\end{array}$ & São Gonçalo & CNSA \\
\hline 46 & Brocoió & $\begin{array}{c}\text { Ilha da Baía de Guanabara } \\
\text { onde foi identificado um } \\
\text { sambaqui }\end{array}$ & $\begin{array}{l}\text { Rio de } \\
\text { Janeiro }\end{array}$ & - \\
\hline 47 & Lagoa & $\begin{array}{l}\text { Sambaqui identificado na } \\
\text { Lagoa Rodrigo de Freitas }\end{array}$ & $\begin{array}{l}\text { Rio de } \\
\text { Janeiro }\end{array}$ & - \\
\hline 48 & Paquetá & $\begin{array}{c}\text { Sambaqui identificado na Ilha } \\
\text { de Paquetá }\end{array}$ & $\begin{array}{l}\text { Rio de } \\
\text { Janeiro }\end{array}$ & - \\
\hline 49 & $\begin{array}{l}\text { Praça de } \\
\text { Bandeira }\end{array}$ & $\begin{array}{c}\text { Sambaqui identificado na } \\
\text { Praça da Bandeira }\end{array}$ & $\begin{array}{l}\text { Rio de } \\
\text { Janeiro }\end{array}$ & $\begin{array}{c}\text { Claudio Mello de Prado } \\
(2017)\end{array}$ \\
\hline
\end{tabular}

A datação mais antiga, em torno de 7000 anos AP, foi obtida para o sambaqui Camboinhas, localizado na entrada da baía. Datações em sambaquis localizados em Santa Catarina, São Paulo e mesmo no Rio de Janeiro indicam que nesse período já haviam sambaquis ativos em diferentes partes do litoral brasileiro, sugerindo que a antiguidade da ocupação da Baía de Guanabara pode ser admitida (KNEIP et al., 2018; FIGUTI et al., 2013; LIMA et al., 2006).

Adentrado para o interior da baía, o sambaqui de Guapi, localizado no município de Guapimirim, apresenta a data mais antiga, indicando que a ocupação da porção NE da baía se deu em torno de 5604-5335 anos cal AP. O padrão de distribuição dos sítios indica Guapi como o mais afastado da atual linha de costa da Baía de Guanabara. Porém, no período de sua construção, o nível do mar estava a cerca de 2,5 a $3 \mathrm{~m}$ acima do atual, e provavelmente as águas da paleobaía estavam a poucos metros de distância do sítio.

No período entre 4500 e 3000 anos AP, havia sambaquis ativos em Duque de Caxias (São Bento), Itaboraí (Sampaio I e Seu Jorge), Guapimirim (Amourins) e Magé (Arapuan e Rio das Pedrinhas) (Figuras 4 e 5). A ampla dispersão e a recorrência de datações (Tabela 2) permitem sugerir que nesse período a sociedade sambaquieira estava em plena expansão no entorno da Baía de Guanabara, assim como identificado em outras regiões do litoral brasileiro (KNEIP et al., 2018; WAGNER, 2009). 
Figura 4 - Mapa de localização dos sambaquis registrados no entorno da BG. Círculos em vermelho indicam sambaquis ativos entre 4000 e 3000 anos AP e círculos sem preenchimento indicam localização aproximada dos sítios.

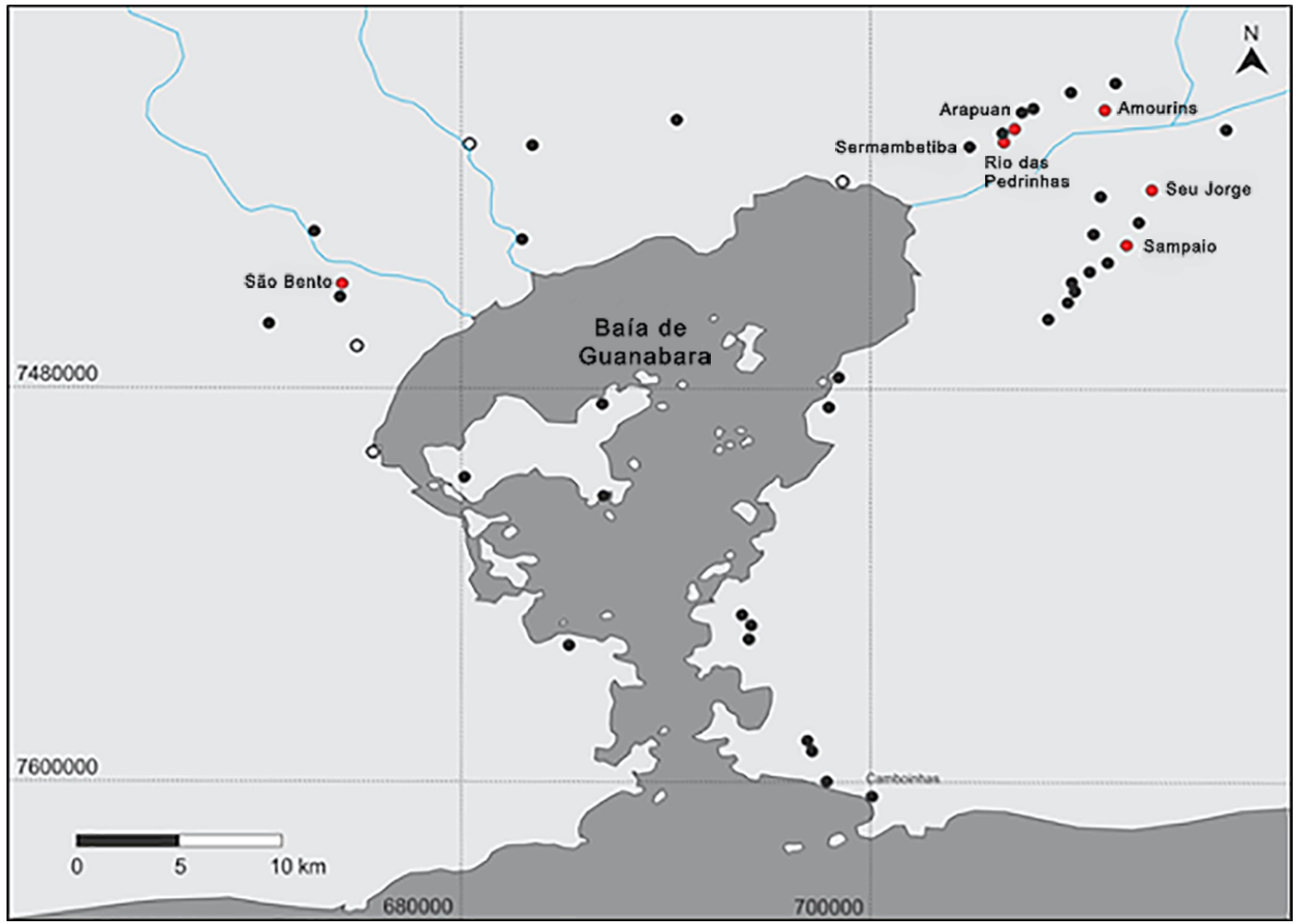

Figura 5 - Datações radiocarbônicas calibradas dos sambaquis localizados no entorno da Baía de Guanabara (OxCal v3.10, BRONK RAMSEY, 1995). Em destaque a faixa cronológica entre 4000 e 3000 anos antes do presente onde ocorre a maior frequência de sambaquis ativos.

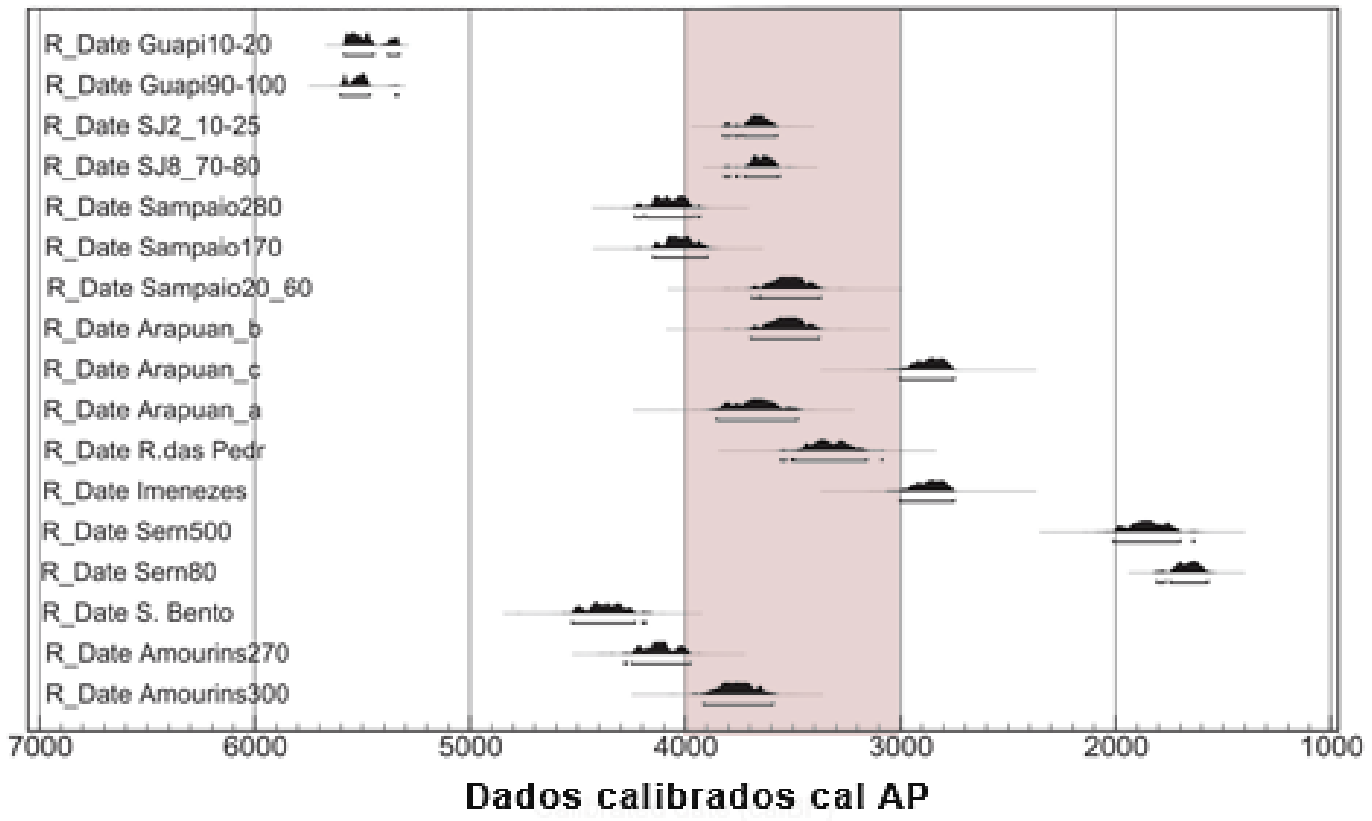


Tabela 2- Datações convencionais e calibradas (2 sigma) dos sambaquis. Calibração feita através do software Calib Radiocarbon Calibration Program (STUIVER \& REIMER, 1993), através da curva de calibração SHcal04 (MCCORMAC et al., 2004) para amostras de carvão e Marine 09 (REIMER et al., 2009) para amostras de conchas.

\begin{tabular}{|c|c|c|c|c|c|c|c|}
\hline Sítio & Localização & $\begin{array}{c}\mathrm{No}^{\mathrm{o}} \\
\text { amostra }\end{array}$ & Material & Método & $\begin{array}{c}\text { Data } \\
\text { Convencional }\end{array}$ & $\begin{array}{c}\text { Data } \\
\text { Calibrada } \\
\text { (2 SIGMA) }\end{array}$ & Referência \\
\hline Amourins & $270 \mathrm{~cm}$ & 259890 & carvão & AMS & $3800 \pm 40$ & $4241-3934$ & Pinto (2008) \\
\hline Amourins & $300 \mathrm{~cm}$ & - & carvão & Conv. & $3530 \pm 60$ & $3898-3577$ & Gaspar (1991) \\
\hline Sernambetiba & $500 \mathrm{~cm}$ & - & carvão & Conv. & $1920 \pm 70$ & $1981-1613$ & Pinto (2008) \\
\hline Sernambetiba & $80 \mathrm{~cm}$ & - & carvão & AMS & $1800 \pm 40$ & $1809-1543$ & Pinto (2008) \\
\hline Guapi & $10-20 \mathrm{~cm}$ & 341740 & carvão & AMS & $4730 \pm 30$ & $5575-5314$ & - \\
\hline Guapi & $90-100$ & 341741 & carvão & AMS & $4790 \pm 30$ & $5584-5326$ & - \\
\hline Seu Jorge & SJ02 & 343430 & carvão & AMS & $3440 \pm 30$ & $3717-3485$ & - \\
\hline Seu Jorge & SJ08 & 343431 & carvão & AMS & $3420 \pm 30$ & $3692-3482$ & - \\
\hline Sampaio I & $\begin{array}{c}\mathrm{S} 1, \mathrm{P} 1, \\
\mathrm{~N} 280 \mathrm{~cm}\end{array}$ & 259892 & carvão & AMS & $3730 \pm 70$ & $4237-3830$ & Pinto (2008) \\
\hline Sampaio I & $\begin{array}{c}\text { S1,P1, } \\
\text { N170cm }\end{array}$ & 259891 & carvão & AMS & $3720 \pm 40$ & $4145-3866$ & Pinto (2008) \\
\hline Sampaio I & $\begin{array}{c}\text { S1,P1, } \\
\text { N20-60 }\end{array}$ & 259893 & carvão & Conv. & $3290 \pm 70$ & $3638-3272$ & Pinto (2008) \\
\hline São Bento & - & 292143 & carvão & Conv. & $3980 \pm 50$ & $4526-4183$ & \\
\hline Arapuã & - & - & conchas & SB & $3460 \pm 70$ & $3516-3156$ & $\begin{array}{l}\text { Mendonça \& } \\
\text { Godoy (2004) }\end{array}$ \\
\hline Arapuã & - & - & conchas & SB & $3340 \pm 70$ & $3363-2990$ & $\begin{array}{l}\text { Mendonça \& } \\
\text { Godoy (2004) }\end{array}$ \\
\hline Arapuã & - & - & conchas & SB & $2800 \pm 60$ & $2697-2356$ & $\begin{array}{l}\text { Mendonça \& } \\
\text { Godoy (2004) }\end{array}$ \\
\hline $\begin{array}{c}\text { Rio das } \\
\text { Pedrinhas }\end{array}$ & - & - & conchas & SB & $3170 \pm 70$ & $3168-2778$ & $\begin{array}{l}\text { Mendonça \& } \\
\text { Godoy (2004) }\end{array}$ \\
\hline Imenezes & - & - & conchas & SB & $2600 \pm 60$ & $2437-2112$ & $\begin{array}{l}\text { Mendonça \& } \\
\text { Godoy (2004) }\end{array}$ \\
\hline
\end{tabular}

A análise da distribuição espacial dos sítios e suas respectivas datações revela uma evidente tendência que indica que a ocupação sambaquieira no entorno da baía de Guanabara seguiu um movimento que acompanhou a dissecação da paleobaía. O sítio mais antigo, Guapi, está localizado mais para o interior, enquanto Sernambetiba, o mais recente, datado entre 2000 a 1800 anos AP, está assentado mais próximo da atual linha de costa da Baía. Essa tendência é também reforçada pelos valores das cotas da base dos sambaquis cada vez mais próximas ao nível do mar atual (Figura 6). 
Figura 6 - Diagrama de datações por radiocarbono em relação à variação de cota das bases dos sambaquis no entorno da Baía de Guanabara (GP - Guapi; AM - Amourins; SJ - Seu Jorge; SM - Sernambetiba). Lucas Garcindo.

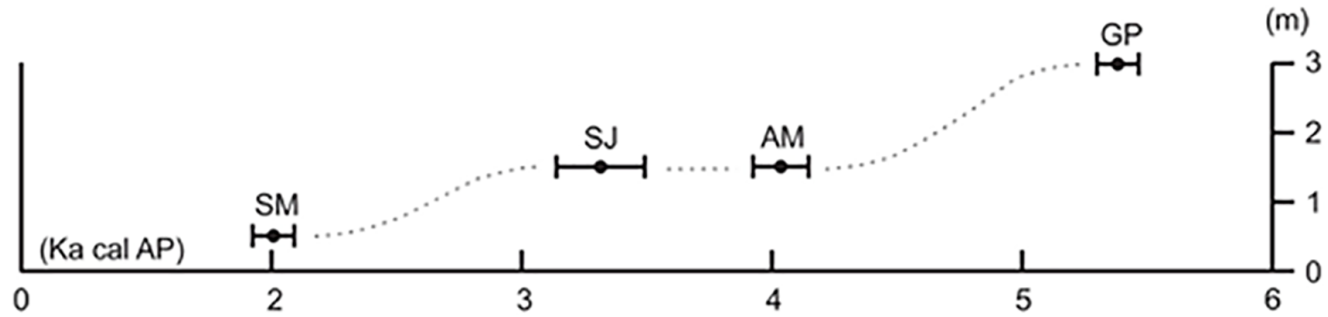

Há 5000 AP, após a última transgressão do Holoceno, o nível do mar estava acima do nível atual, quando os sistemas fluviais do interior da baía foram afogados com a instauração de um ambiente estuarino, com praias de baía e desenvolvimento de pequenos cordões arenosos, que podem ser identificados facilmente por fotografias aéreas. Nesse ambiente foi assentado o sambaqui Guapi.

Com a progressiva regressão ou diminuição do nível do mar e a retomada da sedimentação fluvial em áreas até então afogadas, foram erigidos os sambaquis Amourins, Seu Jorge, Sampaio II, Imenezes, Arapuan e Rio das Pedrinhas, no intervalo de aparente estabilidade do nível do mar entre 4000 e 3000 anos AP.

Finalmente, a cerca de 2000 anos AP, o sambaqui Sernambetiba começa a ser erguido na margem da paleobaía, indicada pelo depósito francamente marinho do concheiro natural sobre o qual o sítio foi construído e que está somente a 0,50 m acima do nível do mar atual, sugerindo a regressão continuada até os dias atuais. Diante desses dados é possível afirmar que os sítios foram sendo construídos com o intuito de permanecerem sempre próximos das águas da Baía de Guanabara.

Tomando a análise da distribuição espacial dos sambaquis da região dos Lagos (GASPAR, 1991), onde os agrupamentos eram compostos entre 5 e 7 sítios, e considerando as informações históricas sobre a destruição de sambaquis e o funcionamento de caieiras no entorno da Baía de Guanabara, foi realizada a projeção apresentada na Figura 7. Para elaboração dessa projeção, foi considerado que cada informação sobre a existência de um sambaqui em uma área específica corresponde a um agrupamento de sítios. Dessa maneira, foi traçado um cenário plausível que não pode ser recomposto em decorrência do intenso processo de urbanização, mas que fornece uma dimensão da ocupação sambaquieira no entorno da Baía de Guanabara. 
Figura 7 - Mapa de projeção dos agrupamentos de sambaquis no entorno da BG.

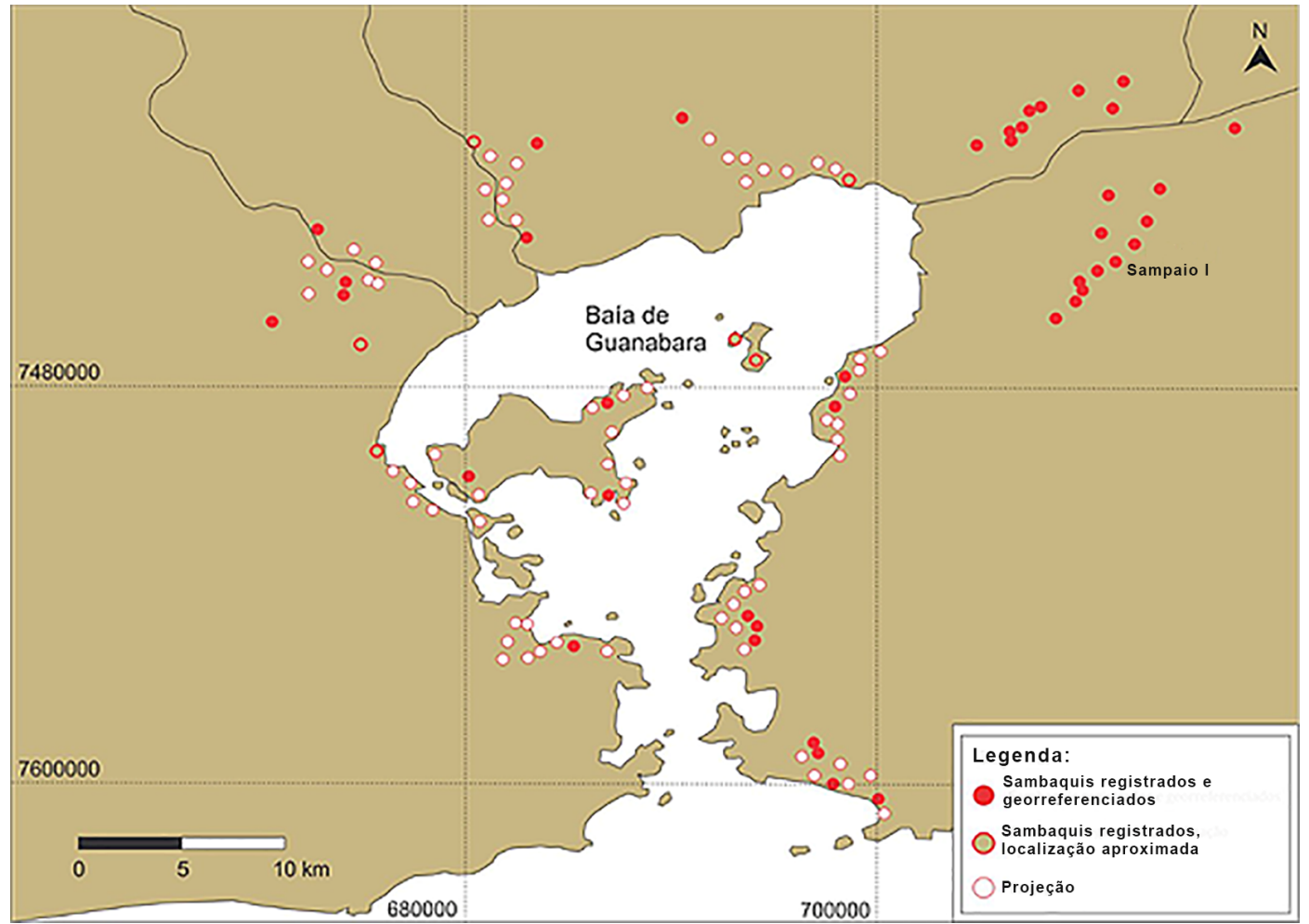

\section{OCUPAÇÃO DA BAIA DE GUANABARA E OUTRAS REGIÕES LITORÂNEAS}

Recentemente, como resultado de pesquisa de longa duração ${ }^{2}$, foi proposto um modelo de ocupação robusto para o litoral Sul de Santa Catarina, região que abrange os municípios de Laguna, Jaguaruna e Tubarão. O mapeamento da distribuição dos sítios, somado ao investimento em datações radiocarbônicas e aos estudos sobre a evolução do sistema paleolagunar, permitiu avançar sobremaneira na compreensão do sistema de assentamento da região (KNEIP, 2004; DEBLASIS et al., 2007; GIANNINI et al., 2010; ASSUNÇÃO, 2010; GASPAR et al., 2014, KNEIP et al., 2018). Nessa área são conhecidos cerca de 100 sambaquis, entre os quais 72 possuem uma ou mais datas, totalizando $200 \mathrm{o}$ número de datações para a região (KNEIP et al., 2018).

O modelo, apoiado em análises geoestatísticas, demonstra que o padrão de distribuição dos sítios em forma de clusters não é aleatório e que os agrupamentos, em número de doze, foram distribuídos em quatro períodos de ocupação: o período inicial, (P1), de 7.500 anos a 4.500 anos aP; (P2), de 4.500 a 3.000 anos aP; (P3), de 3.000 a 2.100 anos aP; e o final, (P4), de 2.100 a 900 anos aP.

Os resultados demonstram que os agrupamentos constituem unidades sociológicas específicas e concomitantes para tal região (KNEIP, 2004; DEBLASIS et al.,2007) e

\footnotetext{
${ }^{2}$ As pesquisas no litoral sul de Santa Catarina tiveram início em 1996 sob a coordenação de Paulo DeBlasis e MaDu Gaspar e atualmente estão organizadas no bojo do Projeto "Sambaqui e Paisagem: modelando a inter-relação entre processos formativos culturais e naturais no litoral sul de Santa Catarina”, Universidade de São Paulo/ FAPESP, e já liberou vários resultados de pesquisas (FISH et al., 2000; KLOKLER, 2000, 2008; KARL, 2000; KNEIP, 2004; DEBLASIS et al., 2007; ASSUNÇÃO, 2010; GIANNINI et al., 2010; GASPAR et al., 2012; SCHEEL-YBERT et al., 2008; BIANCHINI et al., 2011; BENDAZOLLI, 2007; NISHIDA, 2007; PEIXOTO, 2008; BELÉM, 2012; VILLAGRÁN, 2008, GASPAR et al., 2008; 2013, KNEIP et al., 2018).
} 
reforçam a hipótese levantada para a região dos Lagos (GASPAR, 1991) e para o entorno da Baía de Guanabara.

De acordo com a perspectiva que se apoia na evolução do sistema lagunar, os sítios mais antigos (7.500 a 5.500 anos AP) estão localizados no setor interno das lagunas, assentados em terrenos mais elevados. No momento seguinte (5.500 a 4.000 anos AP), há um movimento em direção ao centro da laguna que muito provavelmente se coaduna com o ritmo de assoreamento lagunar centrípeto. Posteriormente (4.000 a 1.700 anos $\mathrm{AP})$, no auge da ocupação, há um deslocamento dos sítios localizados no setor interno para os arredores dos morros e no setor externo para as porções central e norte das lagunas. Por fim (últimos 1.700 anos AP), os sítios se deslocam para o setor externo e, neste momento, as conchas perdem a importância como valor construtivo (GIANNINI et al., 2010).

Outro exemplo de estudo que envolveu o sistema de assentamento da sociedade sambaquieira no litoral foi realizado na Costa Leste da Ilha de São Francisco do Sul, Santa Catarina. De acordo com os resultados, a região foi ocupada de 5.950 anos AP até 1.390 anos AP, sendo que o período de expansão da população está entre 4000 e 3000 anos AP, coincidindo com o modelo anteriormente apresentado. Durante o período de ocupação, verificou-se a presença de agrupamentos de sítios que estavam ativos de forma concomitante e com modelos construtivos similares (SÁ, 2017).

Já no litoral de São Paulo, os modelos de ocupação propostos para as diferentes regiões ocorrem onde há concentrações de sítios (CALIPPO, 2004; 2010). A densidade de sítios é de 69 para a região da Cananéia e 136 para a Baixada Santista. Além disso, é uma região onde a ocupação sambaquieira apresenta grande profundidade temporal, assim como o Rio de Janeiro e o litoral sul de Santa Catarina. As datações mais antigas estão em torno de 8000 anos AP e as mais recentes chegam a 500 anos AP, com um período de expansão entre 5000 e 3000 anos AP (AFONSO, 2017; LIMA, 1999/2000).

O modelo de ocupação proposto para a região da Ilha do Cardoso, em Cananéia, a partir do estudo de 26 sambaquis, indica dois momentos de ocupação. Um entre 8000 e 5.100 anos AP, com um deslocamento dos sítios em direção ao interior, como resposta à transgressão marinha, e outro, a partir de 5.100 anos AP, período em que há um deslocamento dos sítios em direção à costa, acompanhando o rebaixamento do nível do mar, sendo que em ambas as fases ocorrem agrupamentos de sítios (CALLIPO, 2004).

Os dados acima apresentados assim como as datações obtidas para diversos sítios fornecem um panorama que ilustra uma cronologia de ocupação semelhante para os estados do Rio de Janeiro, São Paulo, Paraná e Santa Catarina (Figura 8) (WAGNER, 2009). Especialmente no que se refere aos períodos de início, auge e desestruturação do programa de construção de sambaquis.

Entre 5000 e 3000 anos AP, período em que o nível do mar está em pleno processo regressivo, centenas de sambaquis foram erigidos ao longo da costa, indicando que nem mesmo as mudanças ambientais interferiram na construção de novos assentamentos. Esse aspecto é de extrema relevância, pois contraria o pressuposto de que as mudanças no nível do mar teriam influenciado negativamente no processo de ocupação sambaquieira, algo que por muito tempo se discutiu na pesquisa em sambaquis. Esse período de mudanças ambientais não foi um período de estabilidade, mas sim de plena expansão da sociedade sambaquieira em várias regiões ao longo do litoral brasileiro. 
Figura 8 - Datações dos sambaquis localizados nos estados do Rio de Janeiro, São Paulo e Paraná. (Modificado de Wagner, 2009). Os retângulos destacam o período de maior estabilidade entre 5000 e 3000 anos AP.
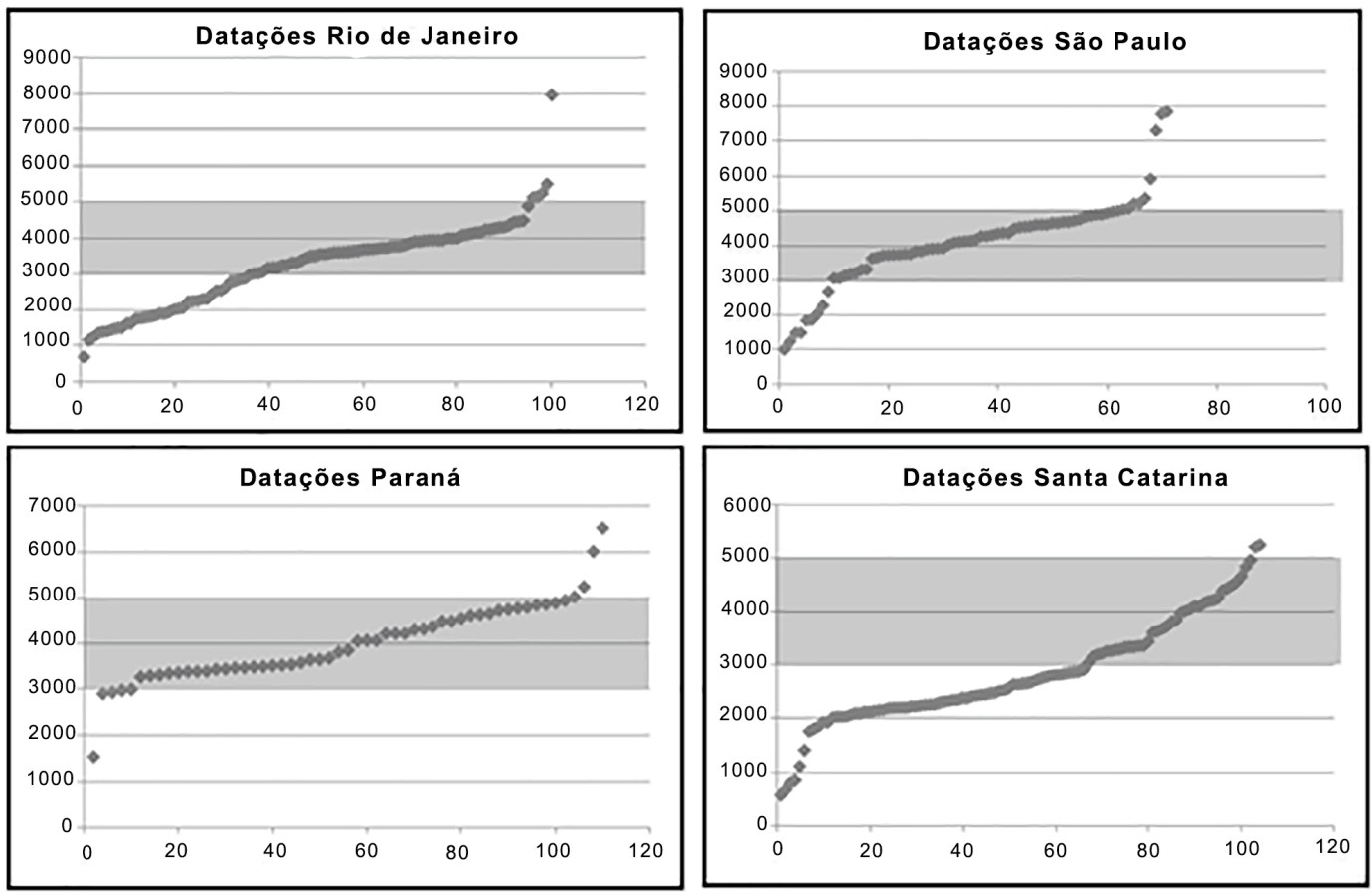

\section{CONCLUSÃO}

A Baía de Guanabara forneceu condições para ocupação sambaquieira ao longo de pelo menos 30 séculos, e as informações disponíveis para a sua porção nordeste, que apresenta excepcional condição de preservação frente à densa urbanização de outras áreas, sugerem significativa densidade de sítios.

No que se refere à dimensão dos pacotes arqueológicos, as raras informações existentes indicam que os sambaquis de maiores dimensões não ultrapassam $6 \mathrm{~m}$ de espessura, independente do período de atividade do assentamento. Trata-se de dimensão compatível com informações sobre sambaquis de outras porções do litoral fluminense que não foram atingidas pela intensa urbanização, como ilha Grande e Saquarema (TENÓRIO, 2004, KNEIP et al., 1981). Como em outras regiões, os agrupamentos reúnem sambaquis de maior e menor porte, o que sugere hierarquia entre assentamentos próximos.

Dessa maneira, constata-se que os sambaquieiros da BG mantiveram as dimensões dos assentamentos ao longo dos períodos de ocupação, muito embora haja fortes indícios, procedentes do estudo de estratigrafia, que compartilhavam a maneira de construção dos sambaquis de grandes dimensões que caracterizam o litoral sul catarinense. Considerando a relação entre dimensões de sítios e das lagoas para o litoral de Santa Catarina, é possível supor que a BG, em decorrência de seu tamanho, não propiciava amplo contato visual como ocorre na lagoa do Camacho, Santa Catarina (OPPITZ, 2011). Aparentemente foi relevante para os pescadores-coletores da BG implantarem seus assentamentos próximos aos rios, como fica evidente no caso do sambaqui de Amourins. Construir em locais um pouco mais protegidos de inundações características da planície guanabarina, garantir porto seguro para embarcações e acesso a porções mais interioranas da baixada devem ter sido aspectos que nortearam as escolhas para inaugurar um novo local para implantação de sambaquis. 
É difícil realizar avaliações sobre densidade de sítios, pois a intensa urbanização não permite que sejam desenvolvidas reflexões mais consubstanciadas. Cabe considerar um provável isolamento em relação a outros grupos, em decorrência da presença da serra Órgãos, que pode ter restringido, durante um longo período, contatos interculturais, porém o que se sabe é que às margens da $\mathrm{BG}$ foi mantido o hábito de construir sambaquis quase sempre com as mesmas dimensões. Contatos com outros grupos só se intensificaram por volta de $2600 \mathrm{com}$ a paulatina invasão do território sambaquieiro pelos ceramistas (SCHEEL-YBERT et al., 2008).

Por outro lado, a interação com outros sambaquieiros deve ter sido recorrente, como parece ter ocorrido em outras regiões da costa brasileira. Cabe lembrar que Prous (1991), ao estudar as regras de fabricação das esculturas recuperadas em sambaquis do sul, chamou a atenção para a existência de unidade cultural (ideológica) que abrangia o litoral da região sul e parte do sudeste.

Considera-se que regras são compartilhadas através da circulação de informações, sendo que a faixa litorânea forma um eixo no sentido norte-sul que propicia a circulação de pessoas. As análises empreendidas nos sítios do sul de Santa Catarina, Vale do Ribeira em São Paulo e entorno da BG sobre o processo de formação de alguns sambaquis também indica fortemente a articulação dos construtores de sambaqui. A identificação de agrupamentos de sambaquis em diferentes porções do litoral sul e sudeste ainda permite afirmar que tratar-se de um padrão de ocupação característico que se perpetuou no tempo e no espaço, demonstrando um sistema sociocultural muito bem estruturado. Por outro lado, as cronologias obtidas para alguns estados também apontam para interconexão entre as diferentes regiões e sugerem que fenômenos relacionados com a expansão e desestruturação do programa de construção de sambaquis, apesar de especificidades regionais, tiveram impactos na região sul e sudeste como um todo. 


\section{REFERÊNCIAS BIBLIOGRÁFICAS}

AFONSO, Marisa. 2017. Arqueologia dos sambaquis no litoral de São Paulo: análise da distribuição dos sítios e cronologia. Especiaria - Cadernos de Ciências Humanas, 17: 203-227.

AMADOR, Elmo da Silva 1974 - Praias Fósseis do Recôncavo da Bala de Guanabara. Anais Academia Brasileira de Ciência, Rio de Janeiro, 46:253-262.

AMADOR, Elmo da Silva. 1997. Baía de Guanabara e ecossistemas periféricos: homem e natureza. 1 ${ }^{\text {a }}$ ed. Rio de Janeiro, Edição do autor. 529pp.

AMADOR, Elmo da Silva. 1980. Assoreamento da Baía de Guanabara - taxas de sedimentação. Anais da Academia Brasileira de Ciências, 52: 723-742.

ANGULO, Rodolfo \& LESSA, Guilherme. 1997. The Brazilian sea-level curves: a critical review with emphasis on the curves from the Paranaguá and Cananéia regions. Marine Geology, 140: 141-166.

ASSUNÇÃO, Danilo C. 2010. Sambaquis da paleolaguna de Santa Marta: em busca do contexto regional no litoral sul de Santa Catarina. Dissertação de Mestrado. São Paulo, Universidade de São Paulo. 146pp.

BECKER, Maria da Conceição. 1965. Boletim geográfico, Rio de Janeiro ANO XXIV, JULHOAGÕSTO DE 1965, N. 187, p. 671

BEGOT, Lígia \& VIANNA, Marcelo. 2014. Legislação Pesqueira Costeira: o caso da Baía de Guanabara, RJ. Boletim do Instituto de Pesca, São Paulo, 40: 497-520.

BELEM, Fabiana R. 2012. Do seixo ao zoólito. A indústria lítica dos sambaquis do sul catarinense: aspectos formais, tecnológicos e funcionais. Dissertação de Mestrado. São Paulo. Universidade de São Paulo. 252pp.

BELTRÃO, Maria C.; HEREDIA, Osvaldo R.; RABELLO, Ângela M.; PEREZ, Rhoneds A. 1982. Pesquisas arqueológicas no sambaqui de Sernambetiba. Arquivos do Museu de História Natural, 7: 145-156.

BELTRÃO, Maria da C. de M.C. 1972. Os Tupinambás do Rio de Janeiro (1200 anos de ocupação). Congresso Indigenista Interamericano, Brasília, 7:3-6.

BELTRÃO, Maria da C. \& KNEIP, Lina .1967. Arqueologia e Geomorfologia: Tentativa de abordagem interdisciplinar. Boletim Carioca de Geografia, Rio de Janeiro, 18: 1-16.

BELTRÃO, Maria da C. 1978 - Pré-história do Rio de Janeiro. Forense, 1ª ed. Rio de Janeiro, 278 pp.

BENDAZZOLI, Cintia. 2007. O processo de formação dos sambaquis: uma leitura estratigráfica do sítio Jabuticabeira II, SC. Dissertação de Mestrado. Universidade de São Paulo. 248p.

BERREDO, Ana Luiza. 2018. Ritual funerário no sambaqui de Amourins: atividades de preparação do terreno para receber o corpo. Dissertação de Mestrado. Rio de Janeiro, Universidade Federal do Rio de Janeiro. 187pp.

BEZERRA, Francisco Otávio da Silva 1977. Resumo do Relatório 02 de Magé. Boletim do Centro Brasileiro de Arqueologia, Rio de Janeiro, 6: 4-13.

BEZERRA, Otávio. 1995. Sambaqui Arapuan, Guapimirim, RJ: Histórico das pesquisas. In: BELTRÃO, M. B (Org.). Arqueologia do Estado do Rio de Janeiro. Arquivo Público do Estado do Rio de Janeiro Niterói:119-128.

BIANCHINI, Gina F.; GASPAR, Maria D.; DEBLASIS, Paulo; SHEEL-YBERT, Rita. 2011. Processo de Formação do sambaqui Jaboticabeira-II: interpretações através da análise estratigráfica de vestígios vegetais carbonizados. Revista do Museu de Arqueologia e Etnologia, 21: 51-69. 
BIANCHINI, Gina Faraco. 2015. Por entre corpos e conchas: prática social e arquitetura de um sambaqui. Tese de Doutorado. Rio de Janeiro, Universidade Federal do Rio de Janeiro. 199pp.

BORGES, Diogo de Souza. 2015. Prepare o terreno, vou construir: Estudo do processo de formação do sambaqui do Guapi. Dissertação de Mestrado. Rio de Janeiro, Universidade Federal do Rio de Janeiro. 121pp.

BRONK RAMSEY, C. 1995. Radiocarbon Calibration and Analysis of Stratigraphy: The OxCal Program Radiocarbon, 37: 425-430.

CNSA. 2019. Cadastro Nacional de Sítios Arqueológicos. Disponível em: <http://portal.iphan.gov.br/pagina/detalhes/1699>. Acesso em 29 mai. 2019.

CALIPPO, Flávio Rizzi. 2004. Os sambaquis submersos de Cananeia, SP Um estudo de caso de arqueologia subaquática. Dissertação de Mestrado. São Paulo, Universidade de São Paulo. 151pp.

CALIPPO, Flávio Rizzi. 2010. Sociedade sambaquieira, comunidades marítimas. Tese de Doutorado. São Paulo, Universidade de São Paulo. 331p.

CAPANEMA, Guilherme. 1876. Os sambaquis. Ensaios de Sciencia, Rio de Janeiro, 1: I: 79-91,

CARDOSO, Lilian. Além das Conchas: Análise Zooarqueológica do Sambaqui de Amourins. 2013. Dissertação de Mestrado. Rio de Janeiro, Universidade Federal do Rio de Janeiro. 176pp.

CARUSO, Francico; SUGUIO, Kenitiro; NAKAMURA, Toshio. 2000. The Quaternary Geological History of the Santa Catarina Southeastern Region (Brazil). Anais da Academia Brasileira de Ciências, Rio de Janeiro, 72: 257-270.

CATANZARO Leonardo F.; BAPTISTA-NETO, José A.; GUIMARÃES, Maurício S.; SILVA, Cleverson G. 2004. Distinctive sedimentary processes in Guanabara Bay - SE/Brazil, based on the analysis of echo-character $(7.0 \mathrm{kHz})$. Revista Brasileira de Geofísica, Rio de Janeiro, 22:6983.

CHAVES, Carla Maria S. 2011. Mapeamento participativo da pesca artesanal da Baía de Guanabara. Dissertação de mestrado. Rio de Janeiro, Universidade Federal do Rio de Janeiro.185 pp.

CLEROT, Leon Francisco. 1928. Sambaquis da Bacia de Macacu. In: Anaes do XX Congresso Internacional de Americanistas, Rio de Janeiro, 2:451-464.

CORDEIRO OLIVEIRA, Jeanne. 2004. A primeira face da tradição - os Goitacá. Da história e identidade dos que não "deitaram letras". Dissertação de Mestrado. Rio de Janeiro, Universidade Severino Sombra. 203pp.

CORREAA, Iran Carlso Stalliviere; PONZI, Vera Regina Abelin; TRINDADE, L.A.F. 1980. Níveis marinhos quaternários da plataforma continental do Rio de Janeiro. In: XXXI Congresso Brasileiro de Geologia. Annais, 578-587.

DEBLASIS, Paulo; KNEIP, Andreas.; SCHEEL-YBERT, Rita.; GIANNINI, Paulo C.; GASPAR, Maria D. 2007. Sambaquis e paisagem: dinâmica natural e arqueologia regional no litoral do sul de Santa Catarina. Arqueologia Sul-Americana, Cauca, 1: 29-61.

DIAS JR., Ondemar Ferreira. 1973. Pesquisas Arqueológicas, Convênio FLUMITUR/IAB. Niterói, FLUMITUR, 5:11-17.

ESTANEK, Angélica. 2016. Preparativos funerários no Sernambetiba - Sambaqui vida e morte. Tese de Doutorado. Rio de Janeiro, Universidade Federal do Rio de Janeiro. 227pp.

FIGUEIREDO JR., Alberto; TOLEDO, Mauro; CORDEIRO, Renato; GODOY, José Marcus; SILVA, Fabiano; VASCONCELOS, Sérgio; SANTOS, Ricardo. 2014. Linked variations in sediment accumulation rates and sea-level in Guanabara Bay, Brazil, over the last 6000 years. Palaeogeography, Palaeoclimatology, Palaeoecology, Québec, 415: 83-90.

FIGUTI, Levy., PLENS, Claudia., DEBLASIS, Paulo. 2013. Small sambaquis and big chronologies: shellmound building and hunter-gatherers in neotropical highlands. In: Proceedings of the $21^{\text {st }}$ 
International Radiocarbon Conference. Paris, July 9-13, 2012. Radiocarbon, Arizona, 55:12151221.

FIPERJ - Fundação Instituto de Pesca do Estado do Rio de Janeiro, 2014. Relatório Anual Fundação Instituto de Pesca do Estado do Rio de Janeiro, Rio de Janeiro. 144p.

FISH, Suzanne; DEBLASIS, Paulo; GASPAR, Maria D.; FISH, Paul R. 2000. Eventos incrementais na construção de sambaquis, litoral sul do Estado de Santa Catarina. Revista do Museu de Arqueologia e Etnologia, São Paulo, 10: 69-87.

GASPAR, Maria Dulce.; KLOKLER; Daniela; BIANCHINI, Gina. 2013. Sambaqui de Amourins: mesmo sítio, perspectivas diferentes. Arqueologia de um Sambaqui 30 anos depois. Revista del Museo de Antropología, Córdoba, 6: 7-20.

GASPAR, Maria Dulce. 2015. Relatório de Solicitação de Liberação de Área - Programa de resgate do patrimônio arqueológico, histórico e cultural do Rio Galeão, Sociedade Amigos do Museu Nacional, Rio de Janeiro. 14 pp.

GASPAR, Maria Dulce; DEBLASIS, Paulo; FISH, Suzane K.; FISH, Paulo. 2008. Sambaqui (Shell Mound) Societies of Coastal Brazil. In: SILVERMAN, H.; ISBELL, W.H. (eds.). Handbook of South American Archaeology, Springer, pp. 319-335.

GASPAR, Maria Dulce; KLOKER, Daniela; DEBLASIS, Paulo. 2014. Were sambaqui people buried in the trash? Archaeology, physical antropology and the evolution of the interpretation of Brazilian Shell Mounds. In: ROKSANDIC, M.; MENDONÇA DE SOUZA, S.; EGGERS, S.; BURCHELL, M.; KLOKLER, D. (Org.), The Cultural Dynamics of Shell-Matrix Sites, University of New Mexico Press: 253-271.

GASPAR, Maria Dulce; KLOKLER Daniela; BIANCHINI, Gina F. 2013. Arqueologia estratégica: abordagens para o estudo da totalidade e construção de sítios monticulares. Boletim do Museu Paraense Emílio Goeldi. Ciências Humanas, 8: 517-533.

GASPAR, Maria Dulce; KLOKLER, Daniela; DEBLASIS, Paulo. 2012. Tradicional Fishing, Mollusk Gathering, and the Sheel Mound Bouilders of Santa Catarina, Brazil. Journal of Ethnobiology, 31: 188-212.

GASPAR, Maria Dulce. 1991. Aspectos da organização social de um grupo de pescadores, coletores e caçadores: Região compreendida entre a Ilha Grande e o delta do Paraíba do Sul, Estado do Rio de Janeiro. Tese de doutorado. São Paulo, Universidade de São Paulo. 362pp.

GASPAR, Maria Dulce. 1996. Datações, construção de sambaqui e identidade social dos Pescadores, Coletores e Caçadores. In: Reunião Científica da Sociedade De Arqueologia Brasileira, Anais, Porto Alegre, PUCRS, pp. 377-398.

GASPAR, Maria Dulce; BUARQUE, Ângela; CORDEIRO, Jeanne; ESCÓRCIO, Eliana. 2007.Tratamento dos Mortos entre os Sambaquieiros, Tupinambá e Goitacá que ocuparam a Região dos Lagos, Estado do Rio de Janeiro. Revista do Museu de Arqueologia e Etnologia, São Paulo, 17:169-189.

GIANNINI, Paulo C.; SAWAKUCHI, André O.; MARTINHO, Caroline T.; TATUMI, Sonia H. 2007. Eolian depositional episodes controlled by Late Quaternary relative sea level changes on the Laguna-Imbituba coast, South Brazil. Marine Geology, New York, 237: 143-168.

GIANNINI, Paulo; VILLAGRÁN, Ximena; FORNARI, Milene; NASCIMENTO, Daniel; MENEZES, Priscila; TANAKA, Ana Paula; ASSUNÇÃO, Danilo; DEBLASIS, Paulo; AMARAL, Paula. 2010. Interações entre evolução sedimentar e ocupação humana préhistórica na costa centro-sul de Santa Catarina, Brasil. Boletim do Museu Paraense Emílio Goeldi, Belém, 5: 105-128.

GUERRA, Antônio Teixeira. 1962. Significado Geomorfológico do Sambaqui de Sernambetiba. Revista Brasileira de Geografia, Rio de Janeiro, 24:65-70. 
HEREDIA, Osvaldo R.; BELTRAO, Maria da Conceição.; OLIVEIRA, Maria D.; GATTI, Marcelo P. 1982. Pesquisas arqueológicas no sambaqui do Amorins. Arquivos do Museu de História Natural, Belo Horizonte, 6-7: 175-186.

HEREDIA, Oswaldo R; BELTRÃO, Maria da Conceição. 1979. Mariscadores e Pescadores préhistóricos do litoral centro-sul Brasileiro. In: XLIII Congresso Internacional de Americanistas, Vancouver, Canadá. Anais...Vancouver, pp.22.

HEREDIA, Oswaldo R; BELTRÃO, Maria da Conceição.1980. Mariscadores e pescadores préhistóricos do litoral centro-sul brasileiro. In: SCHMITZ, P.I. Estudos de arqueologia e préhistória brasileira - em memória de Alfredo Teodoro Rusins, 31: 101-119.

HURT, Wesley R. 1986. Excavations at the Sambaqui de Sernambetiba. Arquivos da Disciplina de Arqueologia, UFRJ, Rio de Janeiro. 12pp.

JABLONSKI, Silvio; AZEVEDO, Alexandre; MOREIRA, Luiz Henrique; SILVA, Orjana. 2002. Levantamento de dados da atividade pesqueira na Baía de Guanabara como subsídio para a avaliação de impactos ambientais e a gestão da pesca: pescadores e embarcações em atividade, produção, e valor do pescado na Baía de Guanabara. IBAMA, Rio de Janeiro. 49 pp.

JICA- Japan International Cooperation Agency (1994) The study on recuperation of the Guanabara Bay ecosystem. Kokusai Kogyo Co. Ltd, Tokyo, 797 pp.

KARL, Rick. 2000. The Relative Chronology of Cultural Episodes at the Coastal Sambaqui Jabuticabeira II, in Santa Catarina, Brasil. Dissertação de mestrado. Tucson, University of Arizona.

KJERVE, Bjorn; RIBEIRO, César Henrique; DIAS, Gilberto; FILIPPO, Alessandro; QUARESMA, Valéria. 1997. Oceanographic characteristics of an impacted coastal bay: Baía de Guanabara, Rio de Janeiro, Brazil.Continental Shelf Research, Abrolhos, 17:1609-1643.

KLOKLER, Daniela. 2001. Construindo ou deixando um sambaqui? Análise de sedimentos de um sambaqui do litoral meridional brasileiro - processos formativos, região de Laguna, SC. Dissertação de Mestrado. São Paulo. Universidade de São Paulo. 174 pp

KLOKLER, Daniela Magalhaes. 2008. Food for body and soul: mortuary ritual in shell mounds (Laguna - Brazil). Tese de doutorado. Tucson, Universidade do Arizona. 368pp.

KNEIP, Andreas. 2004. O Povo da Lagoa: uso do SIG para modelamento e simulação na área arqueológica do Camacho. Tese de Doutorado. São Paulo, Universidade de São Paulo. 171pp.

KNEIP, Andreas; FARIAS, Deisi S.; DEBLASIS, Paulo. 2018. Longa duração e territorialidade da ocupação sambaquieira na laguna de Santa Marta, Santa Catarina. Revista de Arqueologia, Rio de Janeiro, 31:25-51.

KNEIP, Lina M.; PALLESTRINI, Luciana; CUNHA, Fernando. 1981. Pesquisas Arqueológicas no Litoral de Itaipu, Niterói, Rio de Janeiro. $1^{2}$ ed. Rio de Janeiro, Luna. 174pp.

KNEIP, Lina Maria. 1979. Pesquisas de Salvamento em Itaipu, Niterói, Rio de Janeiro. Itaipu Cia. de Desenvolvimento Territorial. Rio de Janeiro, 30pp.

LEONARDOS, Othon Henry. 1938. Concheiros Naturais e Sambaquis. Serviço de Fomento da Produção Mineral, Rio de Janeiro, 37pp.

LIMA, Tania A. 2000. Complexidade emergente entre caçadores/coletores: uma nova questão para a pré-história brasileira. In: IX Congresso da Sociedade de Arqueologia Brasileira, Rio de Janeiro, Anais.

LIMA, Tania A. 2006. O povoamento inicial do continente americano: migrações, contextos, datações. In: SILVA, Hilton P.; RODRIGUES-CARVALHO Claudia. (Org.), Nossa origem. O povoamento das Américas: visões multidisciplinares. Rio de Janeiro, Vieira \& Lent. pp. 77-103.

MACEDO, Antônio Carlos Magalhães. 1965. As microfaunas do Sambaqui de Sernambetiba e do litoral de Magé. Departamento Nacional de Produção Mineral, Rio de Janeiro, 128pp. 
MARTIN, Louis; SUGUIO, Kenitiro; FLEXOR, Jean Marie. 1981-1982. Utilisation des amas coquilliers artificiels dans les réconstructions des anciennes lignes de rivage: exemples brésiliens. Série Geologia, São Paulo, 12: 135-146.

MCCORMAC F. G., HOGG Alan G., BLACKWELL, Paul G.; BUCK Caitlin E.; HIGHAM T. F. G., REIMER P. J. 2004. SHCal04 Southern Hemisphere calibration, 0-11.0 cal kyr BP. Radiocarbon 46(3):1087-92.

MELLO, Claudio Prado de. 2017. Arqueologia Urbana No Rio De Janeiro: Sítio Arqueológico Da Leopoldina. Revista de estudos sobre Jesus Histórico e sua recepção, Rio de Janeiro, 12: 185-216.

MELLO, Elisa \& SOUZA, Arminda. 1977. O Sambaqui de Saracuruna. Nheengatu, 1:43-58.

MENDONÇA DE SOUZA, Alfredo A.C. 1973 - Relatório Preliminar sobre o Sambaqui do Rio das Pedrinhas, RJ-JC-O6, Magé. Rio de Janeiro.?pp.

MENDONÇA DE SOUZA, Alfredo A.C. 1978 - Projeto Vespúcio, I Etapa: Inventário do Patrimônio Arqueológico de Cabo Frio. Relatório à Secretaria de Turismo de Cabo Frio, ms.

MENDONÇA DE SOUZA, Sheila Maria Ferraz; LIRYO, A.; BIANCHINI, Gina Faraco; GASPAR, Maria Dulce. 2012. Sambaqui do Amourins: mortos para mounds? Revista de Arqueologia, Rio de Janeiro, 25: 84-103.

MENDONÇA DE SOUZA, Sheila Maria Ferraz \& MENDONÇA DE SOUZA. Alfredo A. 1981/82. Pescadores e recoletores do litoral do Rio de Janeiro. Arquivo do Museu de História Natural, Rio de Janeiro, 6-7: 109-130.

MENDONÇA DE SOUZA; Sheila Maria Ferraz; MENDONÇA DE SOUZA, Alfredo A.C. \& MENDONÇA DE SOUZA, Maria Arminda. 1978. Novas Consideração sobre o Sambaqui do Rio das Pedrinhas, Magé, Rio de Janeiro. Trabalho apresentado a I Jornada Brasileira de Arqueologia, ISCB, Rio de Janeiro, publicado nos resumos. 60pp.

MENDONÇA, M.L.T.G. \& J.M. GODOY. 2004. Datação radiocarbônica de sítios arqueológicos do tipo sambaqui pela técnica de absorção de $\mathrm{CO}_{2}$ : uma alternativa à síntese benzênica. Química Nova, São Paulo, 27: 323-325.

MEZZALIRA, Sergio. 1946. Sambaqui de Sernambetiba. Departamento Nacional da Produção Mineral, Rio de Janeiro (Notas Preliminares e Estudos, Rio de Janeiro. 37pp.

NISHIDA, Paula. 2007. A Coisa Ficou Preta: Estudo do Processo de Formação da Terra Preta do Sítio Arqueológico Jabuticabeira II. Tese de Doutorado. São Paulo, Universidade de São Paulo. $112 \mathrm{pp}$.

OLIVEIRA, Marlus. 2016. Diagnóstico do Estado da Baía de Guanabara. Rio de janeiro: KCI Technologies. Convênio de Cooperação Técnica: ATN/OC-14223-BR SDP No: SQC No $17 / 2015.497 \mathrm{pp}$.

OPPITZ, Gabriela. 2011. Vivendo a paisagem: Contribuições transdisciplinares para o estudo do contexto regional de sambaquis do litoral central de Santa Catarina. Monografia. Florianópolis, Universidade Federal de Santa Catarina. 137pp.

PALLESTRINI, Luciana \& MORAIS, Jose L. 1980. Arqueologia Pré-Histórica Brasileira. Revista da USP. São Paulo, 28:0-0.

PAZ, Rhoneds Aldora Rodrigues. 1999. Arqueologia da Baía de Guanabara: estudo dos sambaquis do município de Guapimirim. Tese de Doutorado. São Paulo, Universidade de São Paulo. 220pp.

PEIXOTO, Silvia. 2008. Pequenos aos montes: uma análise dos processos de formação dos sambaquis de pequeno porte do litoral sul de Santa Catarina. Dissertação de Mestrado. Rio de Janeiro, Museu Nacional da Universidade Federal do Rio de Janeiro. 160 pp.

PINTO, Diogo de Cerqueira. 2009. Concha sobre concha: construindo sambaquis e a paisagem no Recôncavo da Baía de Guanabara. Dissertação de Mestrado. Rio de Janeiro, Museu Nacional da Universidade Federal do Rio de Janeiro. 161pp. 
PROUS, André. 1991. A pré-história do Estado de Minas Gerais. 2a ed. Ouro Preto, LPH (UFOP), 211-221pp.

PROZEE, 2005. Relatório técnico sobre o censo estrutural da pesca artesanal marítima e estuarina nos Estados do Espírito Santo, Rio de Janeiro, Paraná, Santa Catarina e Rio Grande do Sul. Fundação de Amparo à Pesquisa de Recursos Vivos na Zona Econômica Exclusiva, Itajaí. 151p.

RAMINELLI, Ronald. 2002. Vistas e paisagens: imagens do Rio de Janeiro colonial. Revista de História, 147:33-52.

REIMER P., BAILLIE M., BARD E., BAYLISS A., BECK J., BLACKWELL P., BRONK RAMSEY C., BUCK C., BURR G., EDWARDS R., FRIEDRICH M., GROOTES P., GUILDERSON T., HAJDAS I., HEATON T., HOGG A., HUGHEN K., KAISER K., KROMER B., MCCORMAC F., MANNING S., REIMER R., RICHARDS D., SOUTHON J., TALAMO S., C. TURNEY C., VAN DER PLICHT J., WEYHENMEYER C. 2009. IntCal09 and Marine09 radiocarbon age calibration curves, 0-50,000 years cal BP. Radiocarbon, Arizona, 51:1111-1150.

RUELLAN, Francis. 1944. A evolução geomorfológica da Baía de Guanabara e das regiões vizinhas. Revista Brasileira de Geografia, Rio de Janeiro, 4: 445-508.

SÁ, Júlio Cesar de. 2017. Sambaquis, patrimônio arqueológico na costa leste de São Francisco do Sul/SC: reflexões sobre o território, variações do nível relativo do mar (NRM) no quaternário e tensões atuais. Dissertação de mestrado. Joinville, Universidade da Região de Joinville. 230pp.

SCHEEL-YBERT, Rita; Kita MACARIO; Angela BUARQUE; Roberto M. ANJOS; Mariana BEAUCLAIR, 2008. A new age to an old site: the earliest Tupiguarani settlement in Rio de Janeiro State. Anais da Academia Brasileira de Ciências, 80 (4): 763-770.

SEVRIN-REYSSAC, Josette; MACHADO, Marcio C.; SCHUTZE, Maria Luisa M.; BIBAS, S Gaspar; LIMA, I. Costa de.; LIMA, Costa Araujo \& ESTEVES C. 1979. Biomasse et production du phytoplancton de la baie de Guanabara (État de Rio de Janeiro, Brésil) et du secteur océanique adjacent. Variations de mai à juillet 1978. Bulletin du Museum national d'histoire naturelle, Paris, 4:329-354.

SILVA, Maria A.; SANTOS, Carla; SILVESTRE, Carolina; ANTONIO, Raphael; CUNHA, Ana Beatriz C.; GRALATO, Jaciele; SOUZA, Renata. 2016. Praias da Baía de Guanabara no Estado do Rio de Janeiro. Revista Brasileira de Geomorfologia (Online), São Paulo, 17: 205-225.

STUIVER M.; REIMER P. J., 1993 - Extended 14C data base and revised CALIB 3.0 14C age calibration program. Radiocarbon, 35 (1): 215-230.

SUGUIO, Kenitiro; MARTIN, Louis; BITTENCOURT, Abílio C.; DOMINGUEZ, José M. FLEXOR, Jean M.; AZEVEDO, Antonio E. 1985. Flutuações do nível relativo do mar durante o Quaternário superior no litoral brasileiro e suas implicações na sedimentação costeira. Revista Brasileira de Geociências, São Paulo, 15: 273-286.

TENÓRIO, Maria C. 2004. Identidade cultural e origem dos sambaquis. Revista do Museu de Arqueologia e Etnologia, São Paulo, 14: 169-178.

TOMAZELLI, Luiz Jose. VILLWOCK, Jorge. 2005. Mapeamento geológico de planícies costeiras: o exemplo da costa do Rio Grande do Sul. Gravel, Porto Alegre, 3: 109-115.

VIANNA, Marcelo; ANDRADE-TUBINO, Magda F.; KEUNECKE, Karina A.; ANDRADE Amanda C.; SILVA D.R.; PADULA, Vinícius. 2012. Estado atual de conhecimento sobre a ictiofauna. in: Meniconi M.F.G.; Silva T.A.; Fonseca M.L.; Lima S.O.F.; Lima E.F.A.; Lavrado H.P.; Figueiredo A.G. (Eds.), Baía de Guanabara. Síntese do Conhecimento Ambiental. Vol. II. Biodiversidade. PETROBRAS, Rio de Janeiro, 170-195.

VILLAGRAN, Ximena. 2010. Estratigrafias que falam: geoarqueologia de um sambaqui monumental. São Paulo: Annalume.

WAGNER, Gustavo P. 2009.Sambaquis da barreira da Itapeva: uma perspectiva geoarqueológica. Tese de doutorado. Porto Alegre, Universidade Católica do Rio Grande do Sul. 241pp. 